\title{
Mass Spectrometry-Based Metabolomics Combined with Quantitative Analysis of the Microalgal Diatom (Chaetoceros calcitrans)
}

\author{
Awanis Azizan ${ }^{1}$, M. Maulidiani ${ }^{1,2}$, Rudiyanto R. ${ }^{3}{ }^{(1)}$, Khozirah Shaari ${ }^{1,4}$, \\ Intan Safinar Ismail ${ }^{1,4}\left(\mathbb{D}\right.$, Norio Nagao ${ }^{5}$ and Faridah Abas $1,6, *(\mathbb{D})$ \\ 1 Laboratory of Natural Products, Institute of Bioscience, Universiti Putra Malaysia, Serdang 43400, Selangor, \\ Malaysia; awanis_azizan@yahoo.com (A.A.); maulidiani@umt.edu.my (M.M.); \\ khozirah@upm.edu.my (K.S.); safinar@upm.edu.my (I.S.I.) \\ 2 Faculty of Science and Marine Environment, Universiti Malaysia Terengganu, Kuala Nerus 21030, \\ Terengganu, Malaysia \\ 3 Faculty of Fisheries and Food Science, Universiti Malaysia Terengganu, Kuala Nerus 21030, Terengganu, \\ Malaysia; rudiyanto@umt.edu.my \\ 4 Department of Chemistry, Faculty of Science, Universiti Putra Malaysia, Serdang 43400, Selangor, Malaysia \\ 5 Laboratory of Marine Biotechnology, Institute of Bioscience, Universiti Putra Malaysia, Serdang 43400, \\ Selangor, Malaysia; norio.nagao@upm.edu.my \\ 6 Department of Food Science, Faculty of Food Science and Technology, Universiti Putra Malaysia, \\ Serdang 43400, Selangor, Malaysia \\ * Correspondence: faridah_abas@upm.edu.my; Tel.: +603-97698343
}

Received: 18 February 2020; Accepted: 14 April 2020; Published: 30 July 2020

check for updates

\begin{abstract}
Although many metabolomics studies of higher land plant species have been conducted, similar studies of lower nonland plant species, which include microalgae, are still developing. The present study represents an attempt to characterize the metabolic profile of a microalgal diatom Chaetoceros calcitrans, by applying high-resolution mass spectrometry detection, via Q-ExactiveTM Plus Orbitrap mass spectrometry. The results showed that 54 metabolites of various classes were tentatively identified. Experimentally, the chloroform and acetone extracts were clearly distinguished from other solvent extracts in chemometric regression analysis using PLS, showing the differences in the C. calcitrans metabolome between the groups. In addition, specific metabolites were evaluated, which supported the finding of antioxidant and anti-inflammatory activities. This study also provides data on the quantitative analysis of four carotenoids based on the identification results. Therefore, these findings could serve as a reliable tool for identifying and quantifying the metabolome that could reflect the metabolic activities of $C$. calcitrans.
\end{abstract}

Keywords: microalgal diatom; metabolic profiles; algalomics; chemical markers; UHPLC-MS

\section{Introduction}

The marine diatom Chaetoceros calcitrans, as shown in Figure 1, is unialgal from the class Bacillariophyceae and has long been used in the mariculture industry. Existing research studies show that this microalga presents high metabolic diversity and that it contains materials that can potentially be used as a valuable source of food supplements for human consumption and as a source of therapeutic ingredients for curing human diseases and improving the survival of mariculture species [1,2]. Given their ability to produce photoprotective and photosynthetic pigments, fatty acids, lipids, polysaccharides, amino acids, and sugar-alcohol metabolites, the genus Chaetoceros is well appreciated for its anti-cancer, antioxidant, anti-inflammatory, and anti-tuberculosis activities [1,3-5]. 
Their bioactive metabolites can play important roles in future as chemotaxonomic markers for the identification of species or taxa and for the assessment of biodiversity in its marine habitats in the production of organic matter by phytoplankton microalgae, geographic variation, and seasonality in productivity, thereby revealing local and global changes in marine ecosystems [6]. However, it is also likely that their bioactive metabolites can be altered by changes in gene expression, regulation of protein functions, and in response to changes of different life stages and growth conditions [7]. Therefore, it is of interest to understand more about what is happening to the cellular systems of the diatom species C. calcitrans and to identify potential new molecules since they are ecologically and nutritionally significant to society in diverse ways.

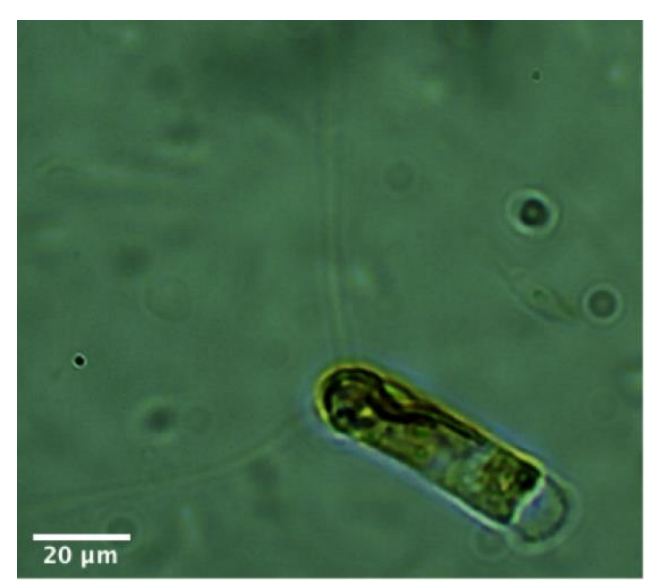

Figure 1. Chaetoceros calcitrans.

The measurement of metabolites can be done using metabolomics and the application of this approaches in diatom research to investigate candidate biomarkers for human health purposes are developing rapidly. In comparison with other omics approaches, including genomics, transcriptomics, and proteomics, metabolomics is still considered as a new aspect in marine diatom research. Thus far, metabolomics-based approaches have proven useful for assessing the effects of Fe limitation in Phaeodactylum tricornutum which they have also combined with the transcriptomic data [8,9], the variations of metabolites in different culture conditions (heterotrophic and mixotrophic) in a green microalga food supplement 'Euglena' [10], key metabolite markers in different growth phases in Skeletonema marinoi, and metabolomics features under different growth phase-dependent markers in cultured diatoms Chaetoceros teneuissimus [7]. Most of these data have been acquired by a GC-MS technique due to its high sensitivity for the identification of volatile and thermally stable metabolites. Therefore, metabolomics offers a unique potential to unravel more on the metabolic features of C. calcitrans underlying the suitable extraction method used and how the identified features are affiliated to the bioactivities.

Previous findings obtained using 1D and 2D NMR spectroscopy via the metabolomics approach revealed that 29 metabolites belonging to various classes, including carotenoids, chlorophylls, fatty acids, amino and organic acids, cholesterol simple sugars, and sugar-alcohol metabolites, were tentatively identified [3]. In addition, the findings showed that there is an established correlation between the metabolite compositions with the biological activities of the microalga extracts prepared from different solvent extraction ranging from polar, semi-polar, and non-polar solvents. Nevertheless, a challenging issue that we are facing using the NMR technique is the congestion and overlapping signals. Hence, further examination of the health-promoting metabolites of $C$. calcitrans using other techniques is believed to be meaningful to overcome these shortcomings and exploring the potential pharmacological relevance of marine diatom.

To obtain a comprehensive 'physiological snapshot' of the diatom cells, advanced analytical tools such as ultra-high performance liquid chromatography-mass spectrometry (UPLC-MS) analysis 
has been used to assess the metabolic level in diatoms, since this tool can provide information on the possible presence of chemical compounds and differentiate the structural classes of metabolites present in minor or trace amounts, without requiring any derivatization across the inherent diversity of metabolites. In interesting works published by Bianco et al. [11] and Cataldi et al. [12] showing the usefulness of the high-resolution MS to determine the positional isomers, the authors proposed a strategy to use the combination of soft-ionization techniques with high-energy collisional dissociation (HCD). The application of such a strategy enabled the location of $\mathrm{C}=\mathrm{C}$ bond between the carbon 7th and 8th of the acyl chain of $\mathrm{N}$-Acylhomoserine lactones (AHLs) discovered in bacteria isolates when a standard LC method is ineffective to resolve the separation of compounds. Within this high-resolution MS/MS capability, the resolved peaks of isobaric precursors or fragments of several classes of metabolites including carotenoids, fatty acids, triacylglycerol, and diacylglycerol enabled accurate assignments to the peak intensity of the diagnostic ions. This is also commonly performed in combination with ultraviolet diode array detectors (UV-DAD). Considering the wide range of metabolites present in C. calcitrans and the influence of solvent extraction when polarity remains indispensable in metabolite extraction, the used of targeted UHPLC-MS in metabolomics analysis is considered to be of importance in revealing a more complete picture of the metabolome $[13,14]$. Nevertheless, no metabolite profiles data are currently available concerning the $C$. calcitrans using the UHPLC-MS approach. Therefore, this study is conducted to fill the gap in current research analysis in monitoring the whole set or at least the medicinally relevant metabolome with no deliberate bias as the UHPLC-MS offers higher sensitivity and selectivity, is quantitatively accurate, and requires smaller amounts of sample than other tools [6].

The present work aims to resolve individual metabolites (polar, semi-polar, and non-polar analytes) extracted from C. calcitrans into separate peaks, enhancing the opportunity to uncover additional metabolites using UHPLC-ESI-Orbitrap MS. High-resolution-MS detection using the Q-Exactive ${ }^{\mathrm{TM}}$ Plus Orbitrap mass spectrometer, which is equipped with Thermo Scientific ${ }^{\mathrm{TM}} \mathrm{Xcalibur}^{\mathrm{TM}}$ software that provides method setup, data acquisition, data processing, and reporting. This benchtop LC-MS system allows the differentiation of minor isotopes, offers greater mass resolutions, mass accuracy and faster scan speed for the analysis of low-abundance metabolites [15]. The tentatively identified metabolites that are found in positive and negative ion modes were listed and discussed. Multivariate data analysis (MVDA), both supervised and un-supervised, was used to classify and relate the identified chemical markers to the ability to protect against oxidation and inflammation. The quantitative analysis of the targeted metabolites of great interest was then assessed to reliably confirm their presence and amount.

\section{Results and Discussion}

\subsection{Identification of Metabolites and Profiling of C. calcitrans Extract by UHPLC-ESI-Orbitrap MS/MS}

The data variations resulting from the phytochemical screening analysis in our previous study [3] suggested that the type of metabolites presented in each extract is a primary factor. To obtain a convincing identification of the metabolites group presented in the extracts, UHPLC-ESI-Orbitrap MS analysis was performed. A total of 54 metabolites belonging to the classes of carotenoids, chlorophylls, fatty acids, glycerolipids, glycerolphospholipids, sterol lipid, (C20 isoprenoids) diterpenes, $N$-acyl-alpha amino acids, and their derivatives, benzoic acid esters, fatty acid esters, fatty amides, and fatty aldehydes, were tentatively characterized in crude extract of $C$. calcitrans prepared from chloroform (Figure 2) by matching the accurate masses, fragmentation pathways, and MS/MS spectral data with the database established and with the available analytical standards. By visual inspection of the representative chromatographic spectrum (Figure 2), the chloroform followed by acetone extracts possessed more intense and prominent peaks with some significant differences compared to the other extracts (hexane, methanol, and $70 \%$ ethanol). Therefore metabolite identification focused on both extracts in the present study. Each of the mass spectra belong to these extracts was provided in the Supplementary Materials for comparison (Supplementary Figures S1-S4). In addition, both extracts exhibited the most significant 
DPPH free radical scavenging and nitric oxide inhibitory activities [3]. When no analytical standards were available for most of the identified compounds, or if they are expensive, identification of the specific metabolites was based upon chromatographic and spectral information, such as retention times, UV spectra, and the presence of fragment ions as reported in the literature. Many of the targeted metabolites were processed using Mass Frontier 3.0 (Thermo Fisher Scientific, San José, CA, USA) to facilitate the prediction of the fragmented ions in both the protonated and deprotonated molecular ion modes using the general and library fragmentation mechanisms. A detailed analysis of each individual metabolite is tabulated in Table 1.

\section{A}

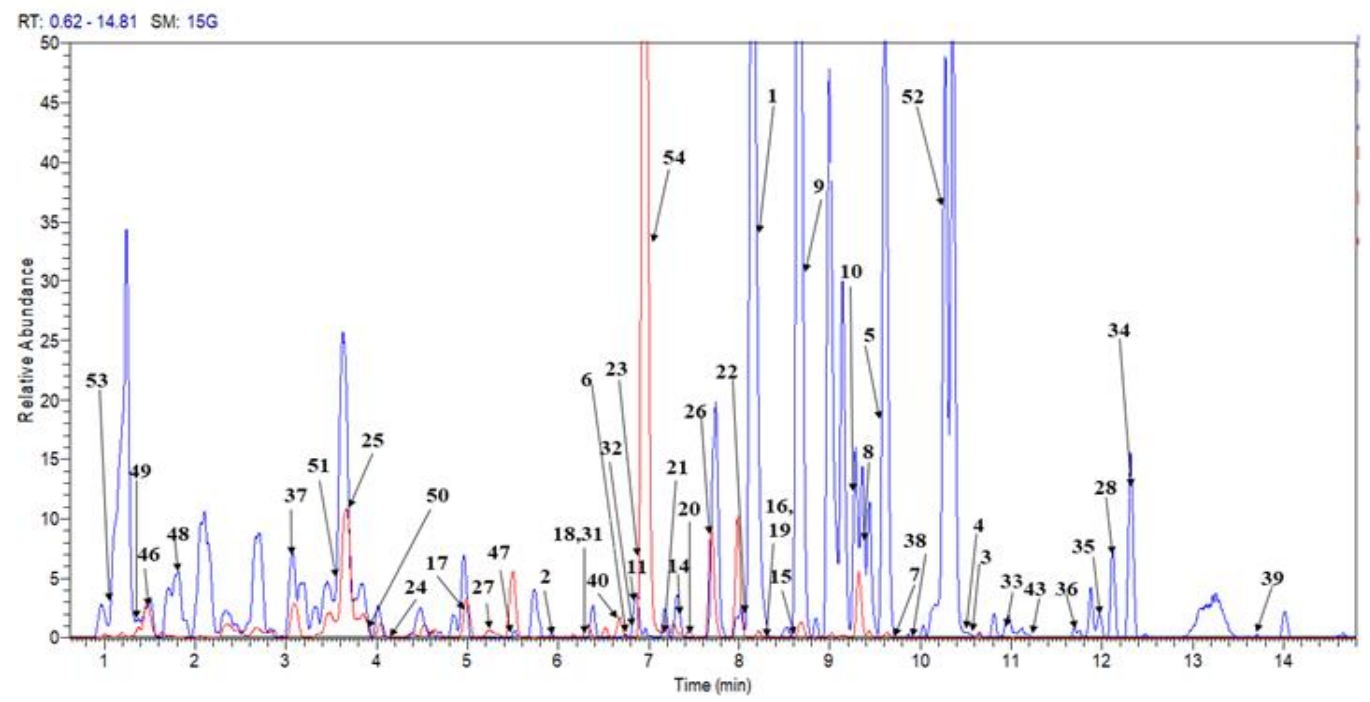

\section{B}

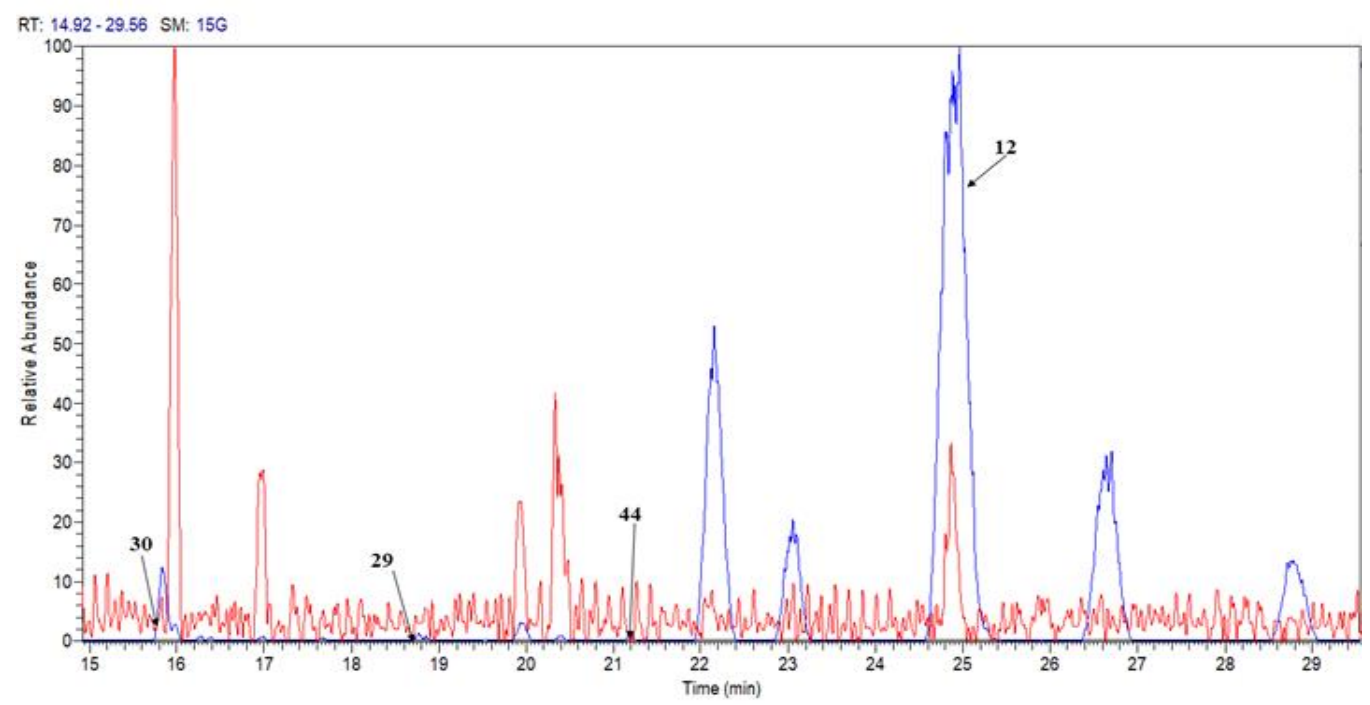

Figure 2. UHPLC-ESI-Orbitrap MS base peak chromatogram of the chloroform extract (A) Retention time 0-15 min (B) Retention time (15-30 min) obtain from microalga diatom C. calcitrans. Blue color represents the chromatogram acquired in positive ion mode whereas red color represents the negative ion mode. For peak assignment see Table 1. 
Table 1. Metabolites identified from C. calcitrans by UHPLC-ESI-Orbitrap MS.

\begin{tabular}{|c|c|c|c|c|c|c|c|c|c|c|}
\hline \multirow[b]{2}{*}{ Peak no. } & \multirow[b]{2}{*}{$t_{\mathrm{R}}(\min )$} & \multirow[b]{2}{*}{ Tentative Identification } & \multirow[b]{2}{*}{ Ion Mode } & \multirow[b]{2}{*}{$\begin{array}{l}\text { Molecular } \\
\text { Formula }\end{array}$} & \multirow[b]{2}{*}{ UV } & \multicolumn{3}{|c|}{$[\mathrm{M}+\mathrm{H}]^{+} /[\mathrm{M}-\mathrm{H}]^{-} m / z$} & \multirow[b]{2}{*}{$\begin{array}{c}\text { Fragment Ions of } \\
{[\mathrm{M}+\mathrm{H}]^{+} /[\mathrm{M}-\mathrm{H}]^{-}}\end{array}$} & \multirow[b]{2}{*}{ Ref. } \\
\hline & & & & & & $\begin{array}{l}\text { Measured } \\
\text { Mass (Da) }\end{array}$ & $\begin{array}{l}\text { Theoretical } \\
\text { Mass (Da) }\end{array}$ & $\begin{array}{l}\text { Mass Error } \\
(\mathrm{ppm})\end{array}$ & & \\
\hline 1 & 8.19 & Fucoxanthin & ESI+ & $\mathrm{C}_{42} \mathrm{H}_{58} \mathrm{O}_{6}$ & 412,442 & 659.4294 & 659.4306 & -1.82 & $\begin{array}{c}\text { 641.4180, 581.3969, } \\
489.2938\end{array}$ & {$[16,17]$} \\
\hline 2 & 5.9 & Fucoxanthinol & ESI+ & $\mathrm{C}_{40} \mathrm{H}_{58} \mathrm{O}_{5}$ & 224,426 & 617.4172 & 617.4200 & 4.53 & $599.4075,581.3972$ & [17] \\
\hline 3 & 10.54 & Lutein & ESI+ & $\mathrm{C}_{40} \mathrm{H}_{56} \mathrm{O}_{2}$ & 226,408 & 569.4210 & 569.4280 & -12.29 & $523.5612,495.3164$ & {$[18,19]$} \\
\hline 4 & 10.52 & Zeaxanthin & ESI+ & $\mathrm{C}_{40} \mathrm{H}_{56} \mathrm{O}_{2}$ & 226,408 & 569.4204 & 569.4280 & -13.34 & 523.5612. & {$[18,19]$} \\
\hline 5 & 9.56 & $\left(3^{\prime} R, 3^{\prime} S\right)$-Astaxanthin & ESI+ & $\mathrm{C}_{40} \mathrm{H}_{52} \mathrm{O}_{4}$ & 474 & 597.3903 & 597.3938 & -5.85 & $\begin{array}{c}147.1163,173.1319 \\
201.1262 \\
\end{array}$ & [19] \\
\hline 6 & 6.73 & Neoxanthin & ESI+ & $\mathrm{C}_{40} \mathrm{H}_{56} \mathrm{O}_{4}$ & 400,420 & 601.4238 & 601.4251 & -2.16 & 583.4016 & {$[6,18]$} \\
\hline 7 & 9.75 & Diadinoxanthin & ESI+ & $\mathrm{C}_{42} \mathrm{H}_{54} \mathrm{O}_{3}$ & 404 & 583.4135 & 583.4145 & 1.71 & $565.4039,547.3956$ & {$[6,18]$} \\
\hline 8 & 9.29 & $\left(3,4,3^{\prime}\right)-4$-Hydroxy-alloxanthin & ESI+ & $\mathrm{C}_{40} \mathrm{H}_{52} \mathrm{O}_{3}$ & 408 & 581.3970 & 581.3989 & -0.69 & 563.3879 & [6] \\
\hline 9 & 8.76 & Canthaxanthin & ESI+ & $\mathrm{C}_{40} \mathrm{H}_{52} \mathrm{O}_{2}$ & 408 & 565.4026 & 565.4040 & -2.48 & 547.3898 & [18] \\
\hline 10 & 9.23 & $14^{\prime}$-apo-beta-carotenal & ESI+ & $\mathrm{C}_{22} \mathrm{H}_{31} \mathrm{O}$ & 414 & 311.2369 & 311.2369 & 0 & 293.2261 & [18] \\
\hline 11 & 6.88 & Chlorophyll c2 & ESI+ & $\mathrm{C}_{35} \mathrm{H}_{28} \mathrm{MgN}_{4} \mathrm{O}_{5}$ & 424 & 609.1981 & 609.1983 & -0.33 & $591.1877,549.1774$ & [20] \\
\hline 12 & 25.49 & Pheophytin a & ESI+ & $\mathrm{C}_{55} \mathrm{H}_{74} \mathrm{MgN}_{4}$ & 506,536 & 871.5694 & 871.5732 & 4.36 & 593.2754 & [20] \\
\hline 13 & 19.26 & Pheophytin b & ESI+ & $\mathrm{C}_{55} \mathrm{H}_{74} \mathrm{MgN}_{6}$ & 536 & 885.5518 & 885.5525 & 0.79 & 593.533 & [20] \\
\hline 14 & 7.31 & Myristic acid & ESI- & $\mathrm{C}_{14} \mathrm{H}_{28} \mathrm{O}_{2}$ & N.D & 227.2104 & 227.2107 & -1.32 & 191.4482 & [21] \\
\hline 15 & 8.58 & Palmitic acid & ESI- & $\mathrm{C}_{16} \mathrm{H}_{32} \mathrm{O}_{2}$ & N.D & 255.2330 & 255.2330 & 0 & 61.98716 & {$[22,23]$} \\
\hline 16 & 8.38 & cis- $\Delta$ 9-Palmitoleic acid & ESI- & $\mathrm{C}_{16} \mathrm{H}_{30} \mathrm{O}_{2}$ & N.D & 253.2175 & 253.2173 & 0.79 & 217.1967 & [22] \\
\hline 17 & 4.96 & 3-Hexadecenoic acid & ESI- & $\mathrm{C}_{16} \mathrm{H}_{30} \mathrm{O}_{2}$ & N.D & 253.2171 & 253.2173 & 1.58 & 141.2954 & [22] \\
\hline 18 & 6.27 & Stearidonic acid & ESI- & $\mathrm{C}_{18} \mathrm{H}_{28} \mathrm{O}_{2}$ & N.D & 275.2015 & 275.2017 & 0 & $231.2124,217.8763$ & [21] \\
\hline 19 & 8.39 & Linoleic acid & ESI- & $\mathrm{C}_{18} \mathrm{H}_{32} \mathrm{O}_{2}$ & N.D & 279.2331 & 279.2330 & 0.36 & 111.3027 & [23] \\
\hline 20 & 7.11 & $\alpha$ or $\gamma$-Linolenic acid & ESI- & $\mathrm{C}_{18} \mathrm{H}_{30} \mathrm{O}_{2}$ & N.D & 277.2173 & 277.2173 & 0 & $69.9031,59.0124$ & [21] \\
\hline 21 & 7.43 & $\alpha$ or $\gamma$-Linolenic acid & ESI- & $\mathrm{C}_{18} \mathrm{H}_{30} \mathrm{O}_{2}$ & N.D & 277.2173 & 277.2173 & 0 & $69.9031,59.0124$ & [21] \\
\hline 22 & 8.11 & Arachidonic acid & ESI- & $\mathrm{C}_{20} \mathrm{H}_{32} \mathrm{O}_{2}$ & N.D & 303.2329 & 303.233 & -0.33 & $287.0870,259.2397$ & {$[21,23]$} \\
\hline 23 & 6.86 & Eicosapentaenoic acid & ESI- & $\mathrm{C}_{20} \mathrm{H}_{30} \mathrm{O}_{2}$ & N.D & 301.2177 & 301.2173 & 0.33 & $273.5861,257.2269$ & {$[21,24]$} \\
\hline 24 & 4.19 & 5 or 15 -HEPE & ESI- & $\mathrm{C}_{20} \mathrm{H}_{30} \mathrm{O}_{3}$ & N.D & 317.2124 & 317.2122 & 0.63 & $255.2231,115.0391$ & [24] \\
\hline 25 & 3.72 & 5 or 15-HEPE & ESI- & $\mathrm{C}_{20} \mathrm{H}_{30} \mathrm{O}_{3}$ & N.D & 317.2132 & 317.2122 & 3.15 & 255.2231 & [24] \\
\hline 26 & 7.63 & Docosahexaenoic acid & ESI- & $\mathrm{C}_{22} \mathrm{H}_{32} \mathrm{O}_{2}$ & N.D & 327.2331 & 327.233 & 0.31 & $283.2432,269.2458$ & [25] \\
\hline 27 & 5.23 & 4,5-Epoxy-17R-HDHA & ESI+ & $\mathrm{C}_{25} \mathrm{H}_{34} \mathrm{O}_{4}$ & N.D & 399.2519 & 399.253 & -2.76 & $321.2201,296.2936$ & [25] \\
\hline 28 & 12.14 & 6-bromo- $\Delta 5$-heptacosadienoic acid & ESI+ & $\mathrm{C}_{27} \mathrm{H}_{50}{ }^{79} \mathrm{BrO}_{2}^{-}$ & N.D & $\begin{array}{l}485.3008, \\
487.2993\end{array}$ & $\begin{array}{l}485.2989, \\
487.2989\end{array}$ & $\begin{array}{l}-3.77 \\
-0.82\end{array}$ & $\begin{array}{c}\text { 405.3321, } 112.5382 \\
57.0341\end{array}$ & [22] \\
\hline
\end{tabular}


Table 1. Cont

\begin{tabular}{|c|c|c|c|c|c|c|c|c|c|c|}
\hline \multirow[b]{2}{*}{ Peak no. } & \multirow[b]{2}{*}{$t_{\mathrm{R}}(\min )$} & \multirow[b]{2}{*}{ Tentative Identification } & \multirow[b]{2}{*}{ Ion Mode } & \multirow[b]{2}{*}{$\begin{array}{l}\text { Molecular } \\
\text { Formula }\end{array}$} & \multirow[b]{2}{*}{ UV } & \multicolumn{3}{|c|}{$[\mathrm{M}+\mathrm{H}]^{+} /[\mathrm{M}-\mathrm{H}]^{-} m / z$} & \multirow[b]{2}{*}{$\begin{array}{l}\text { Fragment Ions of } \\
{[\mathrm{M}+\mathrm{H}]^{+} /[\mathrm{M}-\mathbf{H}]^{-}}\end{array}$} & \multirow[b]{2}{*}{ Ref. } \\
\hline & & & & & & $\begin{array}{l}\text { Measured } \\
\text { Mass (Da) }\end{array}$ & $\begin{array}{l}\text { Theoretical } \\
\text { Mass (Da) }\end{array}$ & $\begin{array}{l}\text { Mass Error } \\
(\mathrm{ppm})\end{array}$ & & \\
\hline 29 & 18.85 & C18:3 $\Delta 6, \Delta 9, \Delta 12 / C 19: 1 \Delta 9$ phosphatidylinositol & ESI+ & $\mathrm{C}_{46} \mathrm{H}_{81} \mathrm{O}_{13} \mathrm{P}$ & N.D & 873.5482 & 873.5488 & -0.69 & 595.2531 & [26] \\
\hline 30 & 15.73 & C16: $1 \Delta 9 /$ C16:0 phosphatidylglycerol & ESI+ & $\mathrm{C}_{38} \mathrm{H}_{73} \mathrm{O}_{1} 0 \mathrm{P}$ & N.D & 721.5011 & 721.5014 & -0.42 & $663.4510,193.1956$ & [27] \\
\hline 31 & 6.28 & C18: $3 \Delta 9, \Delta 12, \Delta 15 / C 13: 0$ phosphatidylglycerol & ESI+ & $\mathrm{C}_{37} \mathrm{H}_{67} \mathrm{O}_{1} 0 \mathrm{P}$ & N.D & 703.4542 & 703.4545 & 0.21 & $671.4276,643.4357$ & [27] \\
\hline 32 & 6.8 & C20:1 $\Delta$ 11/C0:0 phosphatidic acid & ESI+ & $\mathrm{C}_{23} \mathrm{H}_{45} \mathrm{O}_{7} \mathrm{P}$ & N.D & 465.2977 & 465.2976 & 0.21 & $251.1775,197.1311$ & {$[27,28]$} \\
\hline 33 & 10.89 & $\begin{array}{c}\mathrm{C} 22: 3 \Delta 10, \Delta 13, \Delta 16 / \mathrm{C} 22: 5 \Delta 7, \Delta 10, \Delta 13, \Delta 16, \Delta 19 / \mathrm{C} 0: 0 \\
\text { diacylglycerol }\end{array}$ & ESI+ & $\mathrm{C}_{47} \mathrm{H}_{76} \mathrm{O}_{5}$ & N.D & 721.5760 & 721.5765 & 0 & $\begin{array}{l}\text { 316.5049, } 313.1947 \\
173.1183\end{array}$ & [29] \\
\hline 34 & 12.31 & $\begin{array}{c}\mathrm{C} 18: 3 \Delta 9, \Delta 12, \Delta 15 / \mathrm{C} 19: 1 \Delta 9 / \mathrm{C} 20: 5 \Delta 5, \Delta 8, \Delta 11, \Delta 14 \\
\Delta 17 \text { triacylglycerol }\end{array}$ & ESI+ & $\mathrm{C}_{60} \mathrm{H}_{98} \mathrm{O}_{6}$ & N.D & 915.7436 & 915.7407 & 3.17 & 469.3639 & [6] \\
\hline 35 & 12 & $\begin{array}{c}\mathrm{C} 18: 3 \Delta 6, \Delta 9, \Delta 12 / \mathrm{C} 22: 4 \Delta 7, \Delta 10, \Delta 13, \Delta 16 \text { phosphatidic } \\
\text { acid }\end{array}$ & ESI+ & $\mathrm{C}_{43} \mathrm{H}_{71} \mathrm{O}_{8} \mathrm{P}$ & N.D & 747.4981 & 747.4959 & 2.94 & $732.1207,101.112$ & [29] \\
\hline 36 & 11.69 & C20: $5 \Delta 5, \Delta 8, \Delta 11, \Delta 14, \Delta 17 /$ C15: 0 phosphatidylcholine & ESI+ & $\mathrm{C}_{43} \mathrm{H}_{76} \mathrm{NO}_{8} \mathrm{P}$ & N.D & 766.5370 & 766.5381 & -1.43 & $740.5090,631.427$ & [29] \\
\hline 37 & 3.06 & 5-Androstenetriol & ESI+ & $\mathrm{C}_{19} \mathrm{H}_{30} \mathrm{O}_{3}$ & N.D & 307.2272 & 307.2268 & 1.3 & 289.1795 & [29] \\
\hline 38 & 9.88 & C18: $1 \Delta 9 /$ C12: 0 phosphatidic acid & ESI- & $\mathrm{C}_{33} \mathrm{H}_{63} \mathrm{O}_{8} \mathrm{P}$ & N.D & 617.4211 & 617.4188 & 3.72 & 301.2803 & {$[30,31]$} \\
\hline 39 & 13.62 & C17: 0/C22: $5 \Delta 7, \Delta 10, \Delta 13, \Delta 16, \Delta 19 / \mathrm{C} 0: 0$ diacylglycerol & ESI- & $\mathrm{C}_{42} \mathrm{H}_{72} \mathrm{O}_{5}$ & N.D & 655.5309 & 655.5307 & 0.31 & $\begin{array}{l}356.3249,256.2157 \\
115.0359\end{array}$ & [28] \\
\hline 40 & 6.66 & $\begin{array}{c}\text { C20: } 3 \Delta 8, \Delta 11, \Delta 14 / C 20: 5 \Delta 5, \Delta 8, \Delta 11, \Delta 14, \Delta 17 / C 0: 0 \\
\text { diacylglycerol }\end{array}$ & ESI- & $\mathrm{C}_{43} \mathrm{H}_{68} \mathrm{O}_{5}$ & N.D & 663.5026 & 663.4994 & 4.82 & $375.2085,112.9845$ & {$[27,29]$} \\
\hline 41 & 18.04 & $\begin{array}{c}\text { C22: } 2 \Delta 13, \Delta 16 / C 22: 6 \Delta 4, \Delta 7, \Delta 10, \Delta 13, \Delta 16, \Delta 19 / C 0: 0 \\
\text { diacylglycerol }\end{array}$ & ESI- & $\mathrm{C}_{47} \mathrm{H}_{76} \mathrm{O}_{5}$ & N.D & 719.5636 & 719.562 & 2.22 & $664.5043,440.8061$ & {$[29,30]$} \\
\hline 42 & 25.9 & $\begin{array}{c}\text { C16:0/C18: } 2 \Delta 9, \Delta 12 \text { diacylglyceryl-N,N,N-trimethyl } \\
\text { homoserine (DGTS) }\end{array}$ & ESI- & $\mathrm{C}_{44} \mathrm{H}_{81} \mathrm{NO}_{7}$ & N.D & 734.5950 & 734.594 & 1.36 & 386.8379 & [31] \\
\hline 43 & 11.22 & $\begin{array}{c}\text { C16: } 1 \Delta 9 / \mathrm{C} 20: 5 \Delta 5, \Delta 8, \Delta 11, \Delta 14, \Delta 17 \\
\text { phosphatidylglycerol }\end{array}$ & ESI- & $\mathrm{C}_{42} \mathrm{H}_{71} \mathrm{O}_{10} \mathrm{P}$ & N.D & 765.4713 & 765.4712 & 0.13 & $529.2575,253.2171$ & {$[30,32]$} \\
\hline 44 & 21.35 & O-C18:0/C19:0 phosphatidylserine & ESI- & $\mathrm{C}_{43} \mathrm{H}_{86} \mathrm{NO}_{9} \mathrm{P}$ & N.D & 790.5969 & 790.5968 & 0.13 & $283.5096,73.2201$ & {$[27,32]$} \\
\hline 45 & 11.47 & C16:0/C16:0 sulfoquinovosyl diacylglyceride (SQDG) & ESI- & $\mathrm{C}_{41} \mathrm{H}_{78} \mathrm{O}_{12} \mathrm{~S}$ & N.D & 793.5125 & 793.5141 & -2.02 & 227.20132 & [33] \\
\hline 46 & 1.58 & Crocetin dialdehyde & ESI+ & $\mathrm{C}_{20} \mathrm{H}_{24} \mathrm{O}_{2}$ & N.D & 297.1844 & 297.1849 & -1.68 & 213.1372 & {$[34,35]$} \\
\hline 47 & 5.42 & N-butyl-N(2)-[ 2-hydroxy-2-phenylacetyl]-L-serinamide & ESI+ & $\mathrm{C}_{15} \mathrm{H}_{22} \mathrm{~N}_{2} \mathrm{O}_{4}$ & N.D & 295.1634 & 295.1652 & -6.1 & $277.2147,221.118$ & [6] \\
\hline 48 & 1.81 & Formyl 2,4,6-decatrienoate & ESI+ & $\mathrm{C}_{11} \mathrm{H}_{16} \mathrm{O}_{2}$ & N.D & 181.1217 & 181.1223 & -3.31 & $163.111,135.1164$ & {$[36]$} \\
\hline 49 & 1.29 & Dipentyl phthalate & ESI+ & $\mathrm{C}_{18} \mathrm{H}_{26} \mathrm{O}_{4}$ & N.D & 307.1889 & 307.1904 & -4.88 & $163.111,135.1164$ & [6] \\
\hline 50 & 3.98 & Diisooctyl phtalate & ESI+ & $\mathrm{C}_{24} \mathrm{H}_{38} \mathrm{O}_{4}$ & N.D & 413.2677 & 413.2671 & 1.45 & $381.2407,363.2321$ & [6] \\
\hline 51 & 3.57 & 9,11 pentadecadienal & ESI+ & $\mathrm{C}_{15} \mathrm{H}_{26} \mathrm{O}$ & N.D & 223.2047 & 223.2056 & -4.03 & $205.1954,193.1005$ & [37] \\
\hline 52 & 10.26 & $\mathrm{~N}$-stearoyl taurine & ESI+ & $\mathrm{C}_{20} \mathrm{H}_{41} \mathrm{NO}_{4} \mathrm{~S}$ & N.D & 392.2864 & 392.2829 & 8.92 & $150.0262,149.0229$ & [6] \\
\hline 53 & 1.07 & (2,4)-N-isobutyl-6-phenyl-hexa-2,4-dienamide & ESI+ & $\mathrm{C}_{16} \mathrm{H}_{21} \mathrm{NO}$ & N.D & 244.1696 & 244.1696 & 0 & $226.1438,184.0968$ & [6] \\
\hline 54 & 6.97 & $N$-palmitoyl proline & ESI- & $\mathrm{C}_{21} \mathrm{H}_{39} \mathrm{NO}_{3}$ & N.D & 352.2859 & 352.2857 & 0.56 & 116.0705 & [6] \\
\hline
\end{tabular}

$t_{\mathbf{R}}=$ Retention time; N.D = Not Determined; Ref. $=$ Reference. 


\subsubsection{Identification of Carotenoids and Chlorophylls}

In the present study, a total of 13 natural pigments were identified in extracts of Chaetoceros calcitrans; of these, 10 were carotenoids (peaks 1-10) and peaks 11-13 represented chlorophyll and chlorophyll transformation products. Among the carotenoids identified, fucoxanthin was the main pigment accumulated by this marine diatom. Fucoxanthin (Peak 1) which has the empirical molecular formula $\mathrm{C}_{42} \mathrm{H}_{58} \mathrm{O}_{6}$, is indicated in the MS/MS data as listed in Table 1, its UV-vis spectrum at $\left(t_{\mathrm{R}}=8.19\right.$; $\lambda \max =412,442 \mathrm{~nm}$ ) showed an $[\mathrm{M}+\mathrm{H}]^{+}$ion at $m / z 659.4312[16,17]$. For fucoxanthin, the feature of product ions obtained from protonated molecular ions was observed at $\mathrm{m} / \mathrm{z}$ 641.4180; corresponding to the loss of water and $m / z 581.3969$ resulted from the loss of $\mathrm{C}_{2} \mathrm{H}_{9} \mathrm{O}_{3}$. The deacetylated metabolite fucoxanthinol (Peak 2) found in the MS/MS spectrum produced the adduct ions $[\mathrm{M}+\mathrm{Na}]^{+}(\mathrm{m} / \mathrm{z}$ 599.4075) and $\left[\mathrm{M}+\mathrm{H}-\mathrm{H}_{2} \mathrm{O}\right]^{+}(\mathrm{m} / z$ 581.3972) [17].

Peaks 3 and 4 were assigned to lutein $\left(t_{R}=10.54\right)$ and zeaxanthin $\left(t_{R}=10.53\right)$, respectively. They showed protonated ions at $m / z 569.4210$ and 569.4204, respectively. The resolution of lutein and zeaxanthin remained inadequate, and this caused them to coelute as two very close chromatographic peaks. The mass error for both metabolites were high, we speculated that this is attributed to the complex mixtures of crude extracts, very low abundance of peaks 3 and 4 and improper calibration of the system. Nevertheless, the confirmation of identification from those metabolites was achieved based on their elution time and comparison with the analytical standards [18,19]. Both metabolites are isomers and display similar mass spectrometric behavior, yielded the fragment ion $m / z 523.5612$. The fragment ion was formed due to loss of $\mathrm{C}_{2} \mathrm{H}_{5} \mathrm{O}$. In the $\mathrm{MS}^{2}$ spectrum of $\left(3^{\prime}, 3^{\prime}\right)$-astaxanthin in peak 5 , the protonated molecular ion at $m / z 597.3903$ was eluted at retention time $\left(t_{\mathrm{R}}=9.56\right)$. However, the fragment ion $m / z$ 147.1163, which corresponds to the dehydrated terminal ring with loss of water and cleavage at the 7,8 bond $\left(\mathrm{C}_{10} \mathrm{H}_{11} \mathrm{O}\right)$, was also found at quite an intense level [18].

Peak 6 was identified and characterized as the violaxanthin isomer (also known as neoxanthin); it corresponded to the loss of one $\left[\mathrm{M}+\mathrm{H}-\mathrm{H}_{2} \mathrm{O}\right]^{+}$and two water $\left[\mathrm{M}+\mathrm{H}-2 \mathrm{H}_{2} \mathrm{O}\right]^{+}$moieties. In the MS/MS experiments on neoxanthin, the protonated ion, $m / z 601.4238$ was present $[6,18]$. The fragment ions at $m / z 583.4016\left[\mathrm{M}+\mathrm{H}-\mathrm{H}_{2} \mathrm{O}\right]^{+}$and $m / z 565.3912\left[\mathrm{M}+\mathrm{H}-2 \mathrm{H}_{2} \mathrm{O}\right]^{+}$indicated a loss of water from the protonated ion. Peak 7 , which was assigned as diadinoxanthin $\left(t_{R}=9.75\right)$, yielded the $[\mathrm{M}+\mathrm{H}]^{+}$ ion at $m / z 583.4135$ in its MS/MS spectrum [6,18]. The presence of two signals already interpreted as diagnostic fragments of $m / z 565.4039\left[\mathrm{M}+\mathrm{H}-2 \mathrm{H}_{2} \mathrm{O}\right]^{+}$(generated by the loss of two water molecules) and $m / z 547.3956\left[\mathrm{M}+\mathrm{H}-\mathrm{H}_{2} \mathrm{O}\right]^{+}$(produced by the loss of one water molecule from $m / z 565.4039$ after further splitting) were observed.

In the MS/MS experiments, peak 8, which displayed the $[\mathrm{M}+\mathrm{H}]^{+}$ion at 581.3989 was identified as $\left(3 S, 4 S, 3^{\prime} R\right)$-4-hydroxyalloxanthin [6]. The ion at $m / z 563.3879\left(\mathrm{C}_{40} \mathrm{H}_{52} \mathrm{O}_{3}\right)$ was formed by the loss of $\mathrm{H}_{2} \mathrm{O}$, whereas the ion at $m / z 489.3367\left(\mathrm{C}_{40} \mathrm{H}_{52} \mathrm{O}_{3}\right)$ showed the loss of $\mathrm{C}_{4} \mathrm{H}_{11} \mathrm{O}_{2}$ from its precursor ion. Peaks 9 and 10 were determined as canthaxanthin $\left(t_{\mathrm{R}}=8.76\right)$ at $[\mathrm{M}+\mathrm{H}]^{+}(m / z 565.4026)$ and $14^{\prime}$-apo-beta-carotenal $\left(t_{\mathrm{R}}=9.23\right)$ at $[\mathrm{M}+\mathrm{H}]^{+}(\mathrm{m} / \mathrm{z} 311.2369)$ in their MS/MS positive spectra. In the MS/MS spectrum of canthaxanthin, the fragment ion at $m / z 547.3898\left(\mathrm{C}_{40} \mathrm{H}_{51} \mathrm{O}\right)$ results from the loss of $\mathrm{H}_{2} \mathrm{O}$. On the other hand, $14^{\prime}$-apo-beta-carotenal generated fragment ions of $\left[\mathrm{M}+\mathrm{H}-\mathrm{C}_{2} \mathrm{H}_{4}\right]^{+},[\mathrm{M}+\mathrm{H}$ $\left.-\mathrm{C}_{2} \mathrm{H}_{4} \mathrm{O}\right]^{+}$and $\left[\mathrm{M}+\mathrm{H}-\mathrm{C}_{3} \mathrm{H}_{4} \mathrm{O}\right]^{+}$at $m / z$ 283.2412, 267.2106 and 255.2108, respectively, in its high resolution MS/MS spectrum, being great utility for structural confirmation and elucidation [18].

A fragment ion at $m / z 119.09$ was observed in lutein, zeaxanthin, violaxanthin, diadinoxanthin, $\left(3 S, 4 S, 3^{\prime} R\right)$-4-hydroxyalloxanthin and $14^{\prime}$-apo-beta-carotenal. The known fragment ion at $m / z 119.09$ found by $\mathrm{Fu}$, et al. [16] had been confirmed in this experiment, representing the cleavage between carbons 9,10 and $13^{\prime}, 14^{\prime}$.

The metabolite at peak 11 was tentatively identified as chlorophyll $c_{2}$ and peaks 12 and 13 were found to contain chlorophyll transformation products. Peak 11 was identified as chlorophyll $c_{2}$ $\left(t_{\mathrm{R}}=6.88\right)$ based on the $[\mathrm{M}+\mathrm{H}]^{+}(\mathrm{m} / \mathrm{z}$ 609.4522), revealing the loss of carbomethoxy group from the protonated molecular ion, signal at $m / z 549.1774$ and $m / z 591.44$, corresponding to the elimination of water [20]. Peaks 12 and 13 were identified as pheophytin $a$ and pheophytin $b$ as observed in the MS/MS 
spectra, which showed characteristic peaks at $[\mathrm{M}+\mathrm{H}]^{+}\left(\mathrm{m} / z\right.$ 871.5739) and $[\mathrm{M}+\mathrm{H}]^{+}(\mathrm{m} / z$ 885.5518) with elution times of $\left(t_{R}=25.49\right)$ and $\left(t_{R}=19.26\right)$, respectively [20]. The fragment ions observed at $\mathrm{m} / \mathrm{z}$ 593.2754 and $m / z$ 593. 5330 were occurred due to the loss of the phytol group, $\mathrm{C}_{20} \mathrm{H}_{38}$. Collectively, the distribution of the identified cellular pigments suggested that fucoxanthin was more common in diatom C. calcitrans. The observed high peak intensity of all the detected peaks might be explained by the response of this photosynthetic pigment to white light condition and the experiments was best to be performed during transition of exponential and start of stationary phase $[8,9]$. This may also be attributed to the great sensitivity of the high-resolution mass spectrum employed here. The semi-polar solvent such as chloroform and acetone were more appropriate extraction solvents to explore the key-targeted metabolites in the diatom cells of C. calcitrans.

\subsubsection{Identification of Fatty Acids}

Information obtained from negative ionization from MS/MS revealed the presence of characteristic peaks corresponding to fatty acids in C. calcitrans extracts; these are listed in Table 1. Thirteen metabolites with intense deprotonated molecular ions in either the MS or MS/MS spectrum were tentatively identified as fatty acids. The metabolite at peak 14 was assigned as myristic acid [M $\mathrm{H}]^{-}\left(m / z\right.$ 227.2104) $\left(t_{\mathrm{R}}=7.31\right)$ [21]. No fragment ion that matched a reference in the online database or the literature generated from the precursor ion. Peak 15 was identified as palmitic acid $[\mathrm{M}-\mathrm{H}]^{-}$ $(m / z 255.2330)\left(t_{\mathrm{R}}=8.58\right)[22,23]$. Its characteristic fragment was observed at $m / z 61.9871\left(\mathrm{C}_{2} \mathrm{H}_{5} \mathrm{O}_{2}\right)$ due to loss of $\mathrm{C}_{14} \mathrm{H}_{25}$ from the precursor ion. The metabolites at peaks 16 and 17 were matched to cis- $\Delta$ 9-palmitoleic acid and 3-hexadecenoic acid, respectively. The MS/MS spectra of these two fatty acids yielded molecular ions at $[\mathrm{M}-\mathrm{H}]^{-}(m / z 253.2175)\left(t_{\mathrm{R}}=8.38\right)$ and $[\mathrm{M}-\mathrm{H}]^{-}(\mathrm{m} / z 253.2171)$ $\left(t_{\mathrm{R}}=7.69\right)$.

These metabolites yielded fragment ions at $m / z 217.1967\left(\mathrm{C}_{16} \mathrm{H}_{25}\right)$ for cis- $\Delta$ 9-palmitoleic acid and $m / z 141.2954\left(\mathrm{C}_{10} \mathrm{H}_{21}\right)$ for 3-hexadecenoic acid, respectively, indicating loss of $\left[\mathrm{M}-\mathrm{H}-\mathrm{H}_{4} \mathrm{O}_{2}\right]^{-}$and $\left[\mathrm{M}-\mathrm{H}-\mathrm{C}_{6} \mathrm{H}_{8} \mathrm{O}_{2}\right]^{-}$[22]. Peak 18 was assigned to stearidonic acid with a molecular ion at $[\mathrm{M}-\mathrm{H}]^{-}$ $(m / z 275.2015)$, and MS/MS fragments were observed at $m / z 231.2124\left(\mathrm{C}_{17} \mathrm{H}_{27}\right)$ due to loss of the CO group [22]. The metabolite at peak 19 at $\left[\mathrm{M}-\mathrm{H}^{-}(\mathrm{m} / z\right.$ 279.2331) was linoleic acid with deprotonated molecular ion gave fragment ions at $m / z 111.3027\left(\mathrm{C}_{8} \mathrm{H}_{15}\right)\left[\mathrm{M}-\mathrm{H}-\mathrm{C}_{10} \mathrm{H}_{16} \mathrm{O}_{2}\right]^{-}$and $m / z 59.0126$ $\left(\mathrm{C}_{2} \mathrm{H}_{3} \mathrm{O}_{2}\right)\left[\mathrm{M}-\mathrm{H}-\mathrm{C}_{16} \mathrm{H}_{28}\right]^{-}$, respectively [23].

The empirical molecular formula of the metabolites at peaks 20 and 21 were $\mathrm{C}_{18} \mathrm{H}_{30} \mathrm{O}_{2}$, which matches the spectra peaks of the linolenic acid. However, to correctly determine the isomeric position of these acids whether they are $\alpha$-linolenic acid (polyunsaturated $n-3$ (omega-3)) or $\gamma$-linolenic acid (polyunsaturated $n-6$ (omega-6)), analysis of standard should be done to confirm the results. These metabolites showed the same $[\mathrm{M}-\mathrm{H}]^{-}(\mathrm{m} / \mathrm{z}$ 277.2173) based on common fragment masses $\mathrm{m} / \mathrm{z} 69.9031$ $\left(\mathrm{C}_{5} \mathrm{H}_{9}\right)$ and $59.0124\left(\mathrm{C}_{2} \mathrm{H}_{3} \mathrm{O}_{2}\right)$, due to the loss of $\left[\mathrm{M}-\mathrm{H}-\mathrm{C}_{13} \mathrm{H}_{20} \mathrm{O}_{2}\right]^{-}$and $\left[\mathrm{M}-\mathrm{H}-\mathrm{C}_{16} \mathrm{H}_{26}\right]^{-}$ but with the difference peak intensity of these product ions present in the ESI tandem spectrum, suggesting the peak 20 is differ from peak 21 [21,24]. Peaks 22-23 were identified as arachidonic acid and eicosapentaenoic acid (EPA), this $[\mathrm{M}-\mathrm{H}]^{-} \mathrm{m} / \mathrm{z} 303.2329$ and $[\mathrm{M}-\mathrm{H}]^{-} \mathrm{m} / \mathrm{z} 301.2174$, respectively, based on their fragmentation spectra. Arachidonic acid had product ions at at $\mathrm{m} / \mathrm{z} 287.0870 \mathrm{and} \mathrm{m} / \mathrm{z}$ 259.2397 related to loss of a water molecule and a carbonyl group, while EPA with product ions $\mathrm{m} / \mathrm{z}$ 273.5861 [M - $\left.\mathrm{H}-\mathrm{C}_{2} \mathrm{H}_{4}\right]^{-}(28 \mathrm{amu})$ and $m / z 257.2269$ [M - H - COO] $]^{-}(44 \mathrm{amu})[21,23]$.

Peaks 24 and 25 were proposed as HEPEs isomers of EPA, and it could either be 5-HEPE and 15-HEPE [24]. The mass of metabolite at peak 24 are differing by 0.0004 Da from peak 25 , with small differences in their exact masses, therefore we cannot be certain if these two isomers can be distinguish without good chromatography resolution mass spectra. It should be noted here that it was not possible to define the position of hydroxyl relative to the carboxylic group unless further work using commercial standard and exploring another advances method such as ultraviolet photodissociation (UVPD) in a hybrid $\mathrm{MS}^{\mathrm{n}}$ to confirm these peaks identities. Both had molecular ions at $[\mathrm{M}-\mathrm{H}]^{-} \mathrm{m} / z 317.2124$ and $[\mathrm{M}-\mathrm{H}]^{-} \mathrm{m} / z$ 317.2132, and both displayed fragment ions at $m / z 255.2123\left[\mathrm{M}-\mathrm{H}-\mathrm{CH}_{2} \mathrm{O}_{3}\right]^{-}$. Rettner 
et al. [24] presented that the fragment ion at $m / z 115.0391$ seemingly specific to the 5-HEPE MS/MS spectrum which related to the loss of $\left[\mathrm{M}-\mathrm{H}-\mathrm{C}_{15} \mathrm{H}_{22}\right]^{-}$and eluted later than 15-HEPE, therefore we used this information as guide to our identification. The property revealed that diatom cells of C. calcitrans exhibit a varied lipoxygenase (LOX) metabolism of EPA.

Docosahexaenoic acid (DHA) $\left(t_{\mathrm{R}}=7.63\right)$ displayed $[\mathrm{M}-\mathrm{H}]^{-}$at $m / z 327.2330$ (peak 26) and its derivative, 4,5-epoxy-17R-HDHA, had [M $+\mathrm{H}]^{+}$at $\mathrm{m} / z 399.2519$ (peak 27) in positive ion mode [25]. The MS/MS spectrum of DHA displayed fragment ions at $\mathrm{m} / \mathrm{z} 283.2432$, corresponding to $\mathrm{M}-\mathrm{H}-$ $\mathrm{COOH}]^{-}$(45 amu). 4,5-Epoxy-17R-HDHA was assigned based on the fragment ion at $\mathrm{m} / \mathrm{z} 321.2201$ $\left(\mathrm{C}_{23} \mathrm{H}_{29} \mathrm{O}\right)$, which is related to the loss of $\left[\mathrm{M}+\mathrm{H}-\mathrm{C}_{2} \mathrm{H}_{6} \mathrm{O}_{3}\right]^{+}$. Peak 28 was identified as 6-bromo$\Delta 5$-heptacosadienoic acid and was classified as a monosaturated bromo fatty acid [22]. The UHPLC-MS of the brominated fatty acid, 6-bromo-5-heptacosadienoic acid showed mass spectral peaks at $\mathrm{m} / \mathrm{z}$ 485.3008 and 487.2993, which corresponding to the two isotopes of bromine. The product ion at $\mathrm{m} / \mathrm{z}=$ 405.3321 is for the loss of the hydrogen bromide.

\subsubsection{Identification of Glycerolipids, Glycerolphospholipids and Sterol Lipid}

MS/MS spectra interpretation in both ESI+ and ESI- permitted the identification of a total of 16 glycerollipids, glycerolphospholipids and 1 sterol lipid (Table 1). Despite the significant advances of the Orbitrap technology, it should be noted here that, differentiating structural isomers are remains challenging, especially for the complex lipids identified from biological mixtures, this approach does not precisely indicate the positions of the double bond and the stereochemistry. However, derivatization procedure and analyze by using GCMS is one of the promising methods to overcome this problem The high levels of phospholipids found in C. calcitrans are suggested to be related to the biosynthesis of PUFAs, namely, linoleic (18:2n-6), arachidonic (20:4n-6), $a$-linolenic (18:3n-3), eicosapentaenoic (20:5n-3) and docosahexaenoic (22:6n-3) fatty acids biosynthesis. The glycerophospholipids identified in positive ion mode spectra were $\mathrm{C} 18: 3 \Delta 6, \Delta 9, \Delta 12 / \mathrm{C} 19: 1 \Delta 9$ phosphatidylinositol (PI), a phosphatidylinositol at peak 29; C16: $1 \Delta 9 / \mathrm{C} 16: 0$ phosphatidylglycerol (PG) at peak 30 and C18: $3 \Delta 9, \Delta 12, \Delta 15 / \mathrm{C} 13: 0$ phosphatidylglycerol (PG) at peak 31. Both of the latter are phosphatidylglycerol. C20: $1 \Delta$ 11/C0:0 phosphatidic acid (PA), was detected at peak 32, and C18: $3 \Delta 6, \Delta 9, \Delta 12 / C 22: 4 \Delta 7, \Delta 10, \Delta 13, \Delta 16$ phosphatidic acid was detected at peak 35 . Although the existing literature reports that PI is typically detected in negative ion mode [26], in this study PI, which displayed [M+ H] ${ }^{+}$at $m / z 873.5486$ can be clearly detected at peak 29 in the positive ion scan mode MS/MS experiment. The formation of a characteristic product ion at $m / z 595.2532\left(\mathrm{C}_{27} \mathrm{H}_{48} \mathrm{O}_{12} \mathrm{P}\right)$, corresponded to the loss of the $s n-1$ or $\mathrm{s} n-2$ substituent as a ketene yield ion, $\left[\mathrm{M}-\mathrm{H}-\mathrm{C}_{19} \mathrm{H}_{34} \mathrm{O}\right]^{-}$.

Metabolites at peak 30 and 31 were identified as C16: $1 \Delta 9 / \mathrm{C} 16: 0$ phosphatidylglycerol (PG), C18: $3 \Delta 9, \Delta 12, \Delta 15 / \mathrm{C} 13: 0$ phosphatidylglycerol (PG), respectively, based on their fragmentation spectra [27]. C16: $1 \Delta 9 / \mathrm{C} 16: 0$ phosphatidylglycerol (PG) gave $[\mathrm{M}+\mathrm{H}]^{+}$ions at $m / z 721.5011$, had product ions at $[\mathrm{M}$ $\left.+\mathrm{H}-\mathrm{C}_{4} \mathrm{H}_{10}\right]^{+}$and $\left[\mathrm{M}+\mathrm{H}-\mathrm{C}_{25} \mathrm{H}_{53} \mathrm{O}_{9} \mathrm{P}\right]^{+}$whereas $\mathrm{C} 18: 3 \Delta 9, \Delta 12, \Delta 15 / \mathrm{C} 13: 0$ phosphatidylglycerol (PG), $[\mathrm{M}+\mathrm{H}]^{+}$ion at $m / z 703.4542$ with product ions $\left[\mathrm{M}+\mathrm{H}-\mathrm{CH}_{4} \mathrm{O}\right]^{+}$at $m / z 671.4276\left(\mathrm{C}_{36} \mathrm{H}_{64} \mathrm{O}_{9} \mathrm{P}\right)$ and $\left[\mathrm{M}+\mathrm{H}-\mathrm{C}_{3} \mathrm{H}_{8} \mathrm{O}\right]^{+}$at $m / z 643.4357\left(\mathrm{C}_{34} \mathrm{H}_{60} \mathrm{O} 9 \mathrm{P}\right)$. Peak $32\left(t_{\mathrm{R}}=6.80\right)$ was tentatively assigned to $\mathrm{C} 20: 1 \Delta$ 11/C0:0 phosphatidic acid (PA) with product ions $\left[\mathrm{M}+\mathrm{H}-\mathrm{C}_{18} \mathrm{H}_{35}\right]^{+}$and $[\mathrm{M}+\mathrm{H}-$ $\left.\mathrm{C}_{5} \mathrm{H}_{11} \mathrm{O}_{6} \mathrm{P}\right]^{+}$, at $m / z 251.1775\left(\mathrm{C}_{18} \mathrm{H}_{35}\right)$ and $m / z 197.1311$ [27,28]. Peak 35 gave protonated ion $[\mathrm{M}+\mathrm{H}]^{+}$ at $m / z 747.4981\left(\mathrm{C}_{43} \mathrm{H}_{70} \mathrm{O}_{8} \mathrm{P}\right)$, had product ions at $m / z 731.1207\left(\mathrm{C}_{43} \mathrm{H}_{72} \mathrm{O}_{7} \mathrm{P}\right)$ and $100.1120\left(\mathrm{C}_{5} \mathrm{H}_{8} \mathrm{O}_{2}\right)$ [29].

The metabolites at peaks 38,43 and 44 exhibited the $[\mathrm{M}-\mathrm{H}]^{-}$ion at $m / z 617.4211\left(\mathrm{C}_{33} \mathrm{H}_{62} \mathrm{O}_{8} \mathrm{P}\right), \mathrm{m} / \mathrm{z}$ $765.4713\left(\mathrm{C}_{42} \mathrm{H}_{70} \mathrm{O}_{10} \mathrm{P}\right)$ and $m / z 790.5969\left(\mathrm{C}_{43} \mathrm{H}_{85} \mathrm{NO}_{9} \mathrm{P}\right)$ in the negative ion scan mode of the MS/MS experiment] and were identified as C18: $1 \Delta 9 / \mathrm{C} 12: 0$ phosphatidic acid, C16: $1 \Delta 9 / \mathrm{C} 20: 5 \Delta 5, \Delta 8, \Delta 11$, $\Delta 14, \Delta 17$ phosphatidylglycerol and O-C18:0/C19:0 phosphatidylserine [27,30-32].

Four diacylglycerols (DG) were identified; they are listed in Table 1. Peak 33 ( $t_{\mathrm{R}}=10.89 \mathrm{~min}$ ) was C22: $3 \Delta 10, \Delta 13, \Delta 16 / C 22: 5 \Delta 7, \Delta 10, \Delta 13, \Delta 16, \Delta 19 / \mathrm{C} 0: 0$ diacylglycerol gave the $[\mathrm{M}+\mathrm{H}]^{+}$ ion at $m / z 721.5765\left(\mathrm{C}_{47} \mathrm{H}_{76} \mathrm{O}_{5}\right.$, calculated 721.5765 , error, $\left.-0.00 \mathrm{ppm}\right)$ in the positive ion scan mode of the MS/MS mass spectrum [29]. The obtained ion produced of $\left[\mathrm{M}+\mathrm{H}-\mathrm{C}_{25} \mathrm{H}_{41} \mathrm{O}\right]^{+},[\mathrm{M}+\mathrm{H}-$ 
$\left.\mathrm{C}_{25} \mathrm{H}_{44} \mathrm{O}\right]^{+}$and $\left[\mathrm{M}+\mathrm{H}-\mathrm{C}_{37} \mathrm{H}_{56} \mathrm{O}_{3}\right]^{+}$fragments at $m / z 316.5049,313.1947$ and 173.1183 , in the MS/MS experiment. Peaks 39, 40 and 41 showed $[\mathrm{M}-\mathrm{H}]^{-}$ions at $\mathrm{m} / z 655.5309\left(\mathrm{C}_{42} \mathrm{H}_{71} \mathrm{O}_{5}, t_{\mathrm{R}}=13.62 \mathrm{~min}\right), \mathrm{m} / \mathrm{z}$ $663.5026\left(\mathrm{C}_{43} \mathrm{H}_{67} \mathrm{O}_{5}, t_{\mathrm{R}}=6.66 \mathrm{~min}\right)$ and $\mathrm{m} / z 719.5636\left(\mathrm{C}_{47} \mathrm{H}_{75} \mathrm{O}_{5}, t_{\mathrm{R}}=18.04 \mathrm{~min}\right)$, respectively $[28,29]$. The obtained ion produced of $m / z 316.5049\left[\mathrm{M}+\mathrm{H}-\mathrm{C}_{25} \mathrm{H}_{41} \mathrm{O}\right]^{+}, m / z 313.1947\left[\mathrm{M}+\mathrm{H}-\mathrm{C}_{25} \mathrm{H}_{44} \mathrm{O}\right]^{+}$ and $m / z 173.1183\left[\mathrm{M}+\mathrm{H}-\mathrm{C}_{37} \mathrm{H}_{56} \mathrm{O}_{3}\right]^{+}$represent the possible structure for peak 39, C17: 0/C22: 5 $\Delta 7, \Delta 10, \Delta 13, \Delta 16, \Delta 19 / \mathrm{C} 0: 0$ diacylglycerol. Peak 40 was C20: $3 \Delta 8, \Delta 11, \Delta 14 / \mathrm{C} 20: 5 \Delta 5, \Delta 8, \Delta 11$, $\Delta 14, \Delta 17 / \mathrm{C} 0: 0$ diacylglycerol, had product ions at $m / z 375.2085\left(\mathrm{C}_{23} \mathrm{H}_{35} \mathrm{O}_{4}\right)\left[\mathrm{M}-\mathrm{H}-\mathrm{C}_{20} \mathrm{H}_{32} \mathrm{O}^{-}\right.$. Metabolite at peak 41 has $\left[\mathrm{M}-\mathrm{H}-\mathrm{C}_{4} \mathrm{H}_{8}\right]^{-}$and $\left[\mathrm{M}-\mathrm{H}-\mathrm{C}_{19} \mathrm{H}_{35} \mathrm{O}\right]^{-}$ions at $m / z 664.5043\left(\mathrm{C}_{43} \mathrm{H}_{68} \mathrm{O}_{5}\right)$ and $440.8061\left(\mathrm{C}_{19} \mathrm{H}_{35} \mathrm{O}\right)$, respectively, which confirmed it as $\mathrm{C} 22: 2 \Delta 13, \Delta 16 / \mathrm{C} 22: 6 \Delta 4, \Delta 7, \Delta 10, \Delta 13$, $\Delta 16, \Delta 19 / C 0: 0$ diacylglycerol (DG) $[27,29,30]$.The observed peaks for DG might be explained with the limitation of phosphates, which similarly occurred in plants. Due to phosphorus $(\mathrm{P})$ limitation, the glycerolphospholipids, PC and PI are catalyzed by phospholipases to generate phosphocholine, phosphoinositol, and diacyglycerol (DG), respectively [33]. A triacylglycerol (TG) found at peak 34 was identified as C18: $3 \Delta 9, \Delta 12, \Delta 15 / \mathrm{C} 19: 1 \Delta 9 / \mathrm{C} 20: 5 \Delta 5, \Delta 8, \Delta 11, \Delta 14, \Delta 17$ triacylglycerol (TG). The ESI-MS/MS spectrum of peak 34 showed [M $-\mathrm{H}-\mathrm{C}_{31} \mathrm{H}_{56} \mathrm{O}^{-}$ions at $m / z 469.3639$ [6]. Similarly, the detection of TG could result from degradation of phospholipid under P limitation after the enzymes involved in TG biosynthesis are unregulated (i.e., Kennedy pathway) [33].

Other types of glycerolipids were found in the ESI-MS/MS spectrum of $C$. calcitrans at peaks 42 and 45 were C16:0/C18: $2 \Delta 9, \Delta 12$ diacylglyceryl- $N, N, N$-trimethyl homoserine (DGTS) and C16:0/C16:0 sulfoquinovosyl diacylglyceride (SQDG), tentatively identified based on previously reported literature [31,33]. Sterols are essential dietary nutrients for most microalgae. A sterol lipid, 5 -androstenetriol at peak $37\left(t_{\mathrm{R}}=3.06 \mathrm{~min}\right)$ was also detected in $\mathrm{C}$. calcitrans based on $[\mathrm{M}+\mathrm{H}]^{+}$ion at $307.2272\left(\mathrm{C}_{19} \mathrm{H}_{31} \mathrm{O}_{3}\right)$. The obtained ion produced the $\left[\mathrm{M}+\mathrm{H}-\mathrm{C}_{3} \mathrm{H}_{8} \mathrm{O}_{3}\right]^{+}$fragment of 5-androstenetriol at $m / z 215.1790\left(\mathrm{C}_{16} \mathrm{H}_{23}\right)$ in the MS/MS spectrum. Although there is still insufficient information about this mid-chain hydroxyl group at position C-19 type of sterol in C. calcitrans, but they are widespread and abundant in marine sediments [29].

\subsubsection{Identification of Other Possible Compounds}

Other possible metabolites such as crocetin dialdehyde (C20 isoprenoid (diterpene) derivatives, peak 46), $N$-butyl- $N(2)-[(R)-2$-hydroxy-2-phenylacetyl]-L-serinamide ( $N$-acyl-alpha amino acids and derivatives, peak 47), formyl 2,4,6-decatrienoate (peak 48), while peaks 49 and 50 were tentatively identified and characterized as dipentyl phthalate and diisooctyl phthalate (benzoid acid esters derived from the oxidation of fatty acids), 9, 11 pentadecadienal (peak 51) were tentatively identified based on previously reported data [6,30,34-37]. The identity of metabolites at peaks 52, 53, and 54 were identified as fatty amides resulting from McLafferty rearrangement of $\gamma$-cleavage, and compared with the information in the online database [6].

\subsection{Chemometric Analysis of MS Data}

\subsubsection{Discrimination through Unsupervised Principal Component Analysis (PCA)}

Metabolomics provides an alternative strategy to efficiently evaluate high volume information found in UHPLC-ESI-Orbitrap MS analysis. Therefore, for interpreting the datasets of metabolome, a mathematical and statistical method such as chemometrics is required. Scatter plot of PCA suggests the relative variability and similarity among samples whereas the PCA loading plot reveals the area of the spectra that lead to the clustering plot. In this section, the web-based platform XCMS Online was employed, and the extracted mass signals obtained in both positive and negative ionization modes were then subjected into chemometrics analysis. The results for both scan modes showed a clear variation through two principal components (PC1 and PC2). The first two PC accounted $91.54 \%$ of total variance with chloroform and acetone extracts clustered in the lower and upper chamber of right quadrant, whereas the rest of the extracts were observed on the left side. The ethanol and methanol 
extracts were clustered together in the positive PC2 upper chamber while hexane extract clustered in the negative side of PC2 (Figure 3A). The PCA score plot modeled from negative ionization mode accumulated variance of $98.88 \%$ from the original data, and demonstrated that chloroform and acetone extracts were correlated and separated from the rest of extracts by PC1 and PC2 (Figure 3C). In PCA score plots, chloroform and acetone extracts were observed in the right side, but the position was switched either in positive or negative quadrant of PC1.

A

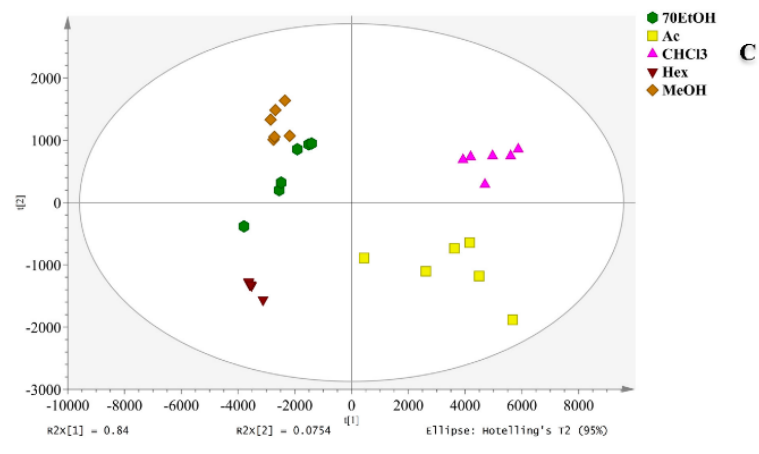

B

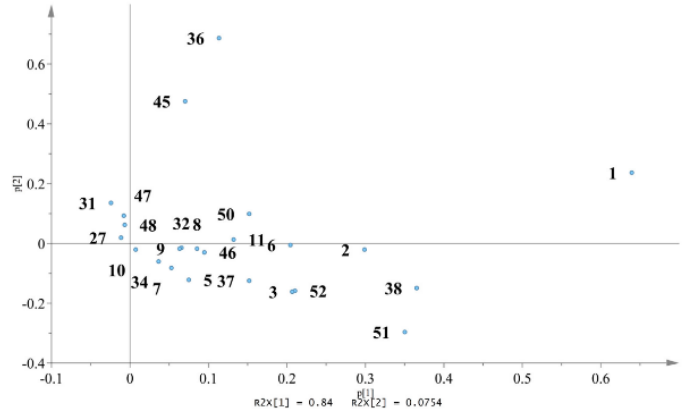

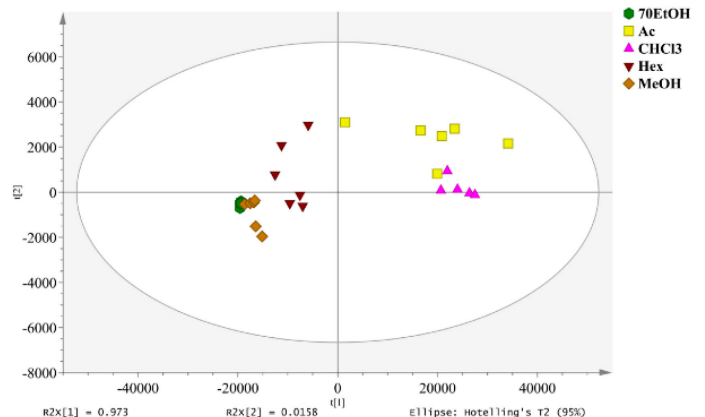

D

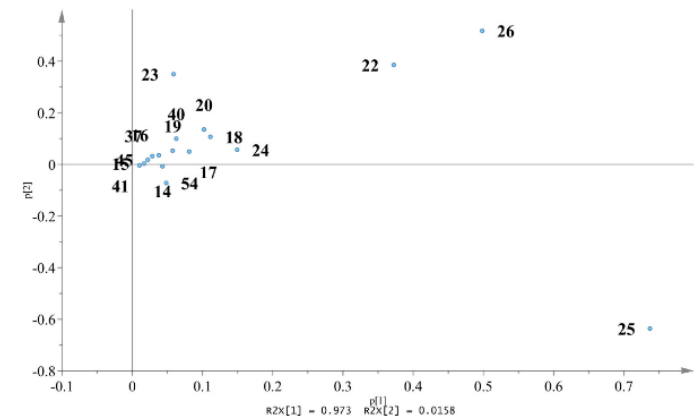

Figure 3. (A) Score plot (B) loading plots of two-dimensional principal component analysis (2D-PCA) in the microalga diatom C. calcitrans in positive ionisation. (C) Score plot (D) loading plots of two-dimensional principal component analysis (2D-PCA) in the microalga diatom C. calcitrans in negative ionisation $(\mathrm{Ac})$ Acetone, $\left(\mathrm{CHCl}_{3}\right)$ Chloroform, $(\mathrm{Hex})$ Hexane, $(\mathrm{MeOH})$ Methanol and $(70 \mathrm{EtOH})$ 70\% Ethanol.

The segregation profiles of each extract observed in scatter plot directly contribute to the distribution of variables positioned in the same dimension in PCA loading plot. The distance of variables from the plot origin is useful for interpretation. The further away the points of variable from the $(0,0)$ coordinates either negatively or positively, the stronger their influence on the model. As revealed in Figure 3B run in positive ion mode, the notable predominant metabolites fucoxanthin (1), C18: $1 \Delta$ 9/C12: 0 phosphatidic acid (PA) (38), C20: $5 \Delta 5, \Delta 8, \Delta 11, \Delta 14, \Delta 17 / C 15$ : 0 phosphatidylcholine (PC) (36) and 9E,11Z pentadecadienal (51) contributed positively to PC1, while MS peak for PG $(18: 3(9,12,15) / 13: 0)$ contributed negatively to PC1. On the other hand, the PCA loading plot for negative ion mode revealed the influential metabolites to segregation pattern included arachidonic acid (22), eicosapentaenoic acid (23), 15-HEPE (25), and docosahexanoic acid (26) (Figure 3D).

2.2.2. Correlation of the Metabolites with Antioxidant and Anti-Inflammatory Activities Using Partial Least Square (PLS) Regression Analysis

Subsequently, PLS was employed by merging the information of the peaks of MS spectra as X variables and the biological activities as $Y$ variables. In addition, variable importance in the projection (VIP) was used to mark the X variables that had influenced in the PLS model as shown in Figure 4B,D. The PLS biplot obtained from positive ion mode exhibited the values of total sum-of-variation in $Y$ explained by the model, $R^{2} Y=0.795$ with good predictive ability with $Q^{2}=0.715$ whereas the PLS 
model acquired from negative ion mode dataset was statically adequate with values $R^{2} Y=0.788$ and goodness of prediction, $Q^{2}=0.691$. The PLS biplot models were formed in a similar way as those exhibited in PCA (Figure 4A,C). The following discussion will be examined in the sequence of high to low significant of the groups and metabolites in the tested bioactivities. The notable metabolites found in positive ion mode included 9,11 pentadecadienal (51), C18: $1 \Delta 9 / \mathrm{C} 12: 0$ phosphatidic acid (PA) (38) and fucoxanthinol (2), were ranked in the top five highest among the $X$ variables analyzed in VIP values list, were found in chloroform and acetone extracts, were found to have positive correlation with DPPH free scavenging activity. Fucoxanthin (1) and C20: $5 \Delta 5, \Delta 8, \Delta 11, \Delta 14, \Delta 17 / C 15$ : 0 phosphatidylcholine (PC) (36) (compounds with VIP value $\geq 1.0$ ) which were also well correlated with chloroform and acetone extracts, were located in the negative side of PC2 and therefore were negatively correlated with the observed $Y$ variables. These metabolites are valuable to evaluate as they might provide indirect effect on reducing the tested bioactivities. 15-HEPE (25), docosahexaenoic acid (26), 5-HEPE (24), eicosapentaenoic acid (23), and 3-hexadecenoic acid (17) (VIP value $\geq 1.0$ ) were obtained in negative ion mode of MS spectra. They were occupied in chloroform and acetones extracts either in lower or upper chamber and were positioned close to the $Y$ variables. The metabolites had positive correlations with bioactivities were 15-HEPE (25), 5-HEPE (24), and 3-hexadecenoic acid (17). Note that, from the PLS biplot, no tentatively identified metabolites were observed in the hexane extract, which might indicate that this extract was inactive towards the bioactivities. Both models were shown to have a satisfactory level of validity as evidenced by the results of permutation test and regression analysis (Supplementary Figures S5 and S6).

A

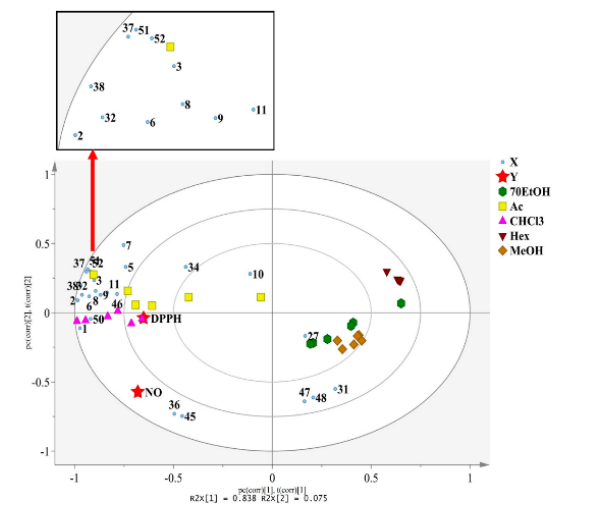

B
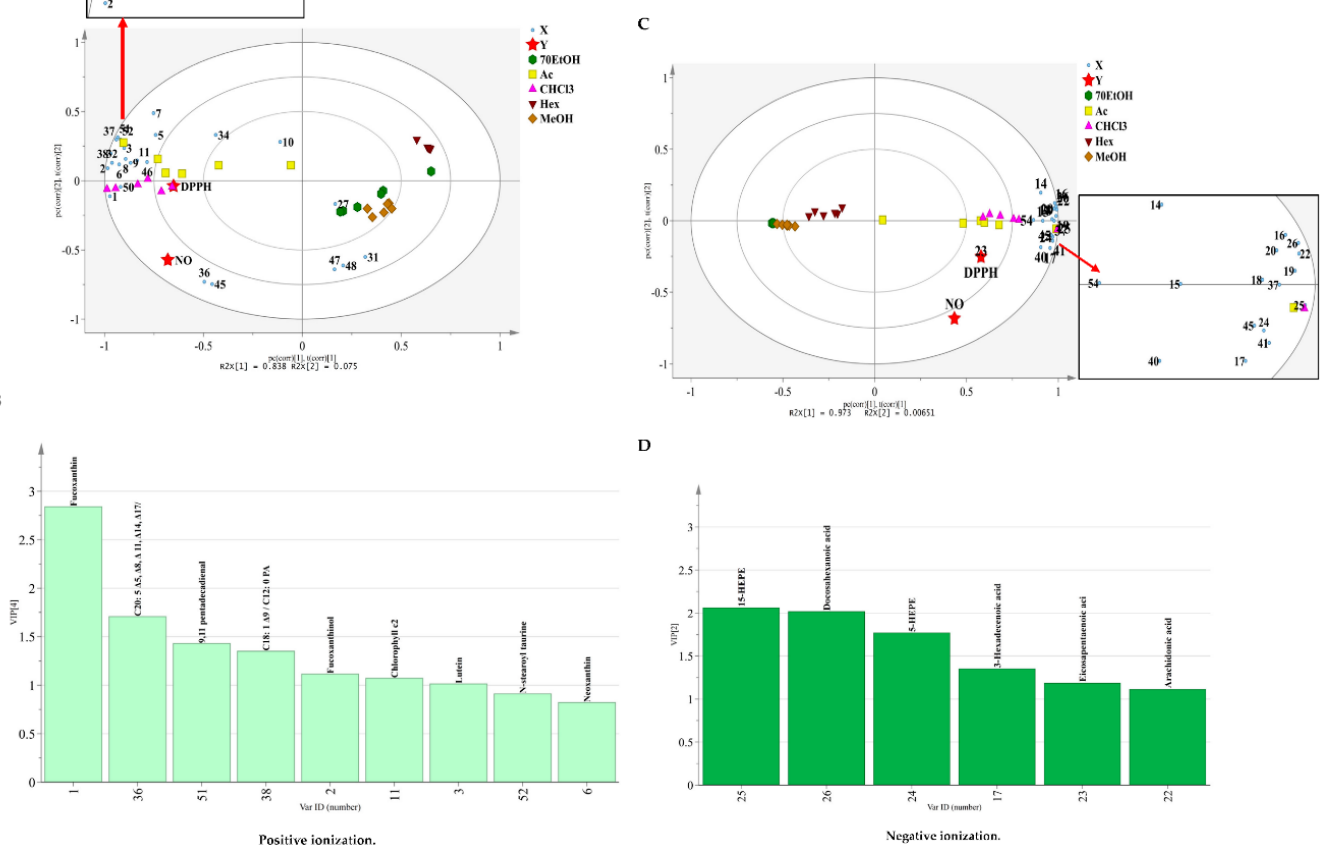

D

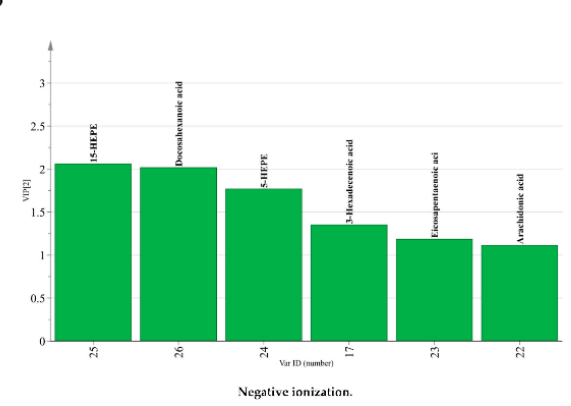

Figure 4. The PLS analysis for (A) correlation between identified metabolites in positive ionization (mass signals data) with biological activities (B) The variable importance in the projection (VIP) values ( $\geq 1$, positive mode) (C) The PLS analysis showing correlation between identified metabolites in negative ionization based on the mass signals obtained from UPLC-MS analysis and the biological activities (D) The variable importance in the projection (VIP) values ( $\geq 1$, negative mode). NO: NO inhibitory; DPPH: DPPH scavenging activities. (Ac) Acetone, $\left(\mathrm{CHCl}_{3}\right)$ Chloroform, (Hex) Hexane, $(\mathrm{MeOH})$ Methanol and (70EtOH) $70 \%$ Ethanol. 
The correlation was further evaluated by computing the Pearson correlation and the correlogram plot were then produced (Figure 5) to confirm the strength of correlation with several variables. Only metabolites with values $\geq 1.0$ were highlighted for both scan modes, which in total 15 metabolites were selected. The obtained correlogram showed strong and significant correlations for fucoxanthinol (2) and chlorophyll c2 (11) with the two biological activities (Figure 5A). The free radical scavenging capacities of these metabolites have been revealed in previous studies [38-40]. Further, 3-Hexadecenoic acid (17) was found to be significantly correlated with NO inhibitory activity but not with DPPH. Meanwhile, arachidonic acid (22) was weakly linked (light red) with NO inhibitory and DPPH activities (Figure 5B). Docosahexaenoic acid (26) was also found to weakly link with NO inhibitory activity (Figure 5B).
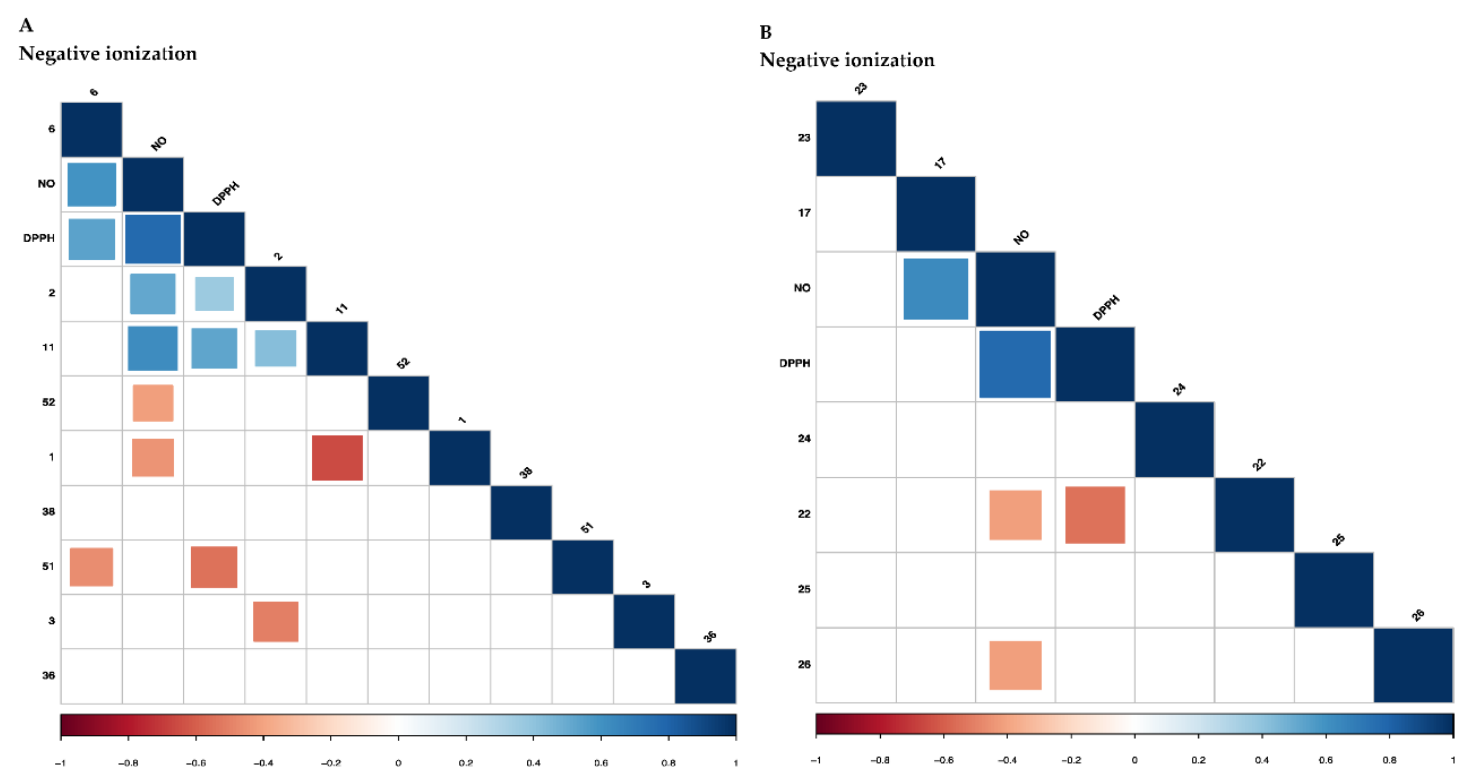

Figure 5. Correlogram visualizing correlation between metabolites analyzed using UHPLC-ESI-Orbitrap MS analysis and biological activities. Correlation with $p$-value $>0.05$ are considered insignificant and are represented by the blank white space. Color and size of the squares are proportional to the correlation coefficients. Positive correlations are shown in blue (different shades; dark blue with the strongest correlation) whereas negative correlations in red (ranging from light red to medium red; dark red with the weakest correlation). Assignment of metabolites: (A) Positive ionization UHPLC-MS: 6, Neoxanthin; 2, Fucoxanthinol; 11, Chlorophyll c2; 52, N-stearoyl taurine; 1, Fucoxanthin; 38, C18: $1 \Delta$ 9/C12: 0 phosphatidic acid (PA); 51, 9,11 pentadecadienal; 3, Lutein; 36, C20: $5 \Delta 5, \Delta 8, \Delta 11, \Delta 14$, $\triangle$ 17/C15: 0 phosphatidylcholine (PC); (B) Negative ionization UHPLC-MS: 23, Eicosapentaenoic acid; 17, 3-Hexadecenoic acid; 24, 5-HEPE; 22, Arachidonic acid; 25, 15-HEPE; 26, Docosahexaenoic acid.

\subsection{Quantification of the Metabolites in Microalgal Diatom C. calcitrans Extracts through} UHPLC-ESI-Orbitrap MS

\subsubsection{Relative Quantification of Metabolites in C. calcitrans}

A total of 15 metabolites (positive ion mode $=9$ and negative ion mode $=6$ ) with VIP scores $\geq 1.0$ were relatively quantified using SPSS 16.0 and are displayed in bar chart to further support the obtained results. The intensity of the metabolites was calculated based on the mean peak area generated from MS spectra. The discussion focuses on the chloroform and acetone extracts, as most metabolites that contribute to the measured bioactivities are highly concentrated in both extracts. The extracts contained high level of fucoxanthin, C20: $5 \Delta 5, \Delta 8, \Delta 11, \Delta 14, \Delta 17 / \mathrm{C} 15$ : 0 phosphatidylcholine (PC), 9,11 pentadecadienal, C18: $1 \Delta$ 9/C12: 0 phosphatidic acid (PA), fucoxanthinol, chlorophyll c2, $\mathrm{N}$-stearoyl taurine and neoxanthin, 15-HEPE, docosahexanoic acid, 5-HEPE and arachidonic acid as 
shown in Figure 6A,B. Fucoxanthinol and chlorophyll c2 were found to be significantly abundant $(0.010 \geq p>0.001)$ in extracts of chloroform and acetone. This was supported by previous study that also identified the fucoxanthinol from medium polar extract of C. calcitrans [39,40]. On the contrary, chlorophyll c2 has been identified from the buffer extract [5]. Additionally, chloroform and acetone extracts contained a comparable amount of (E)-3-hexadecenoic acid (not significant, $p \geq 0.005$ ) and eicosapentaenoic acid (highly significant, $p \leq 0.001$ ) among others (Supplementary Table S1). It is notable that the extract prepared from medium polar solvent could retain a large number of hydrophobic molecules.

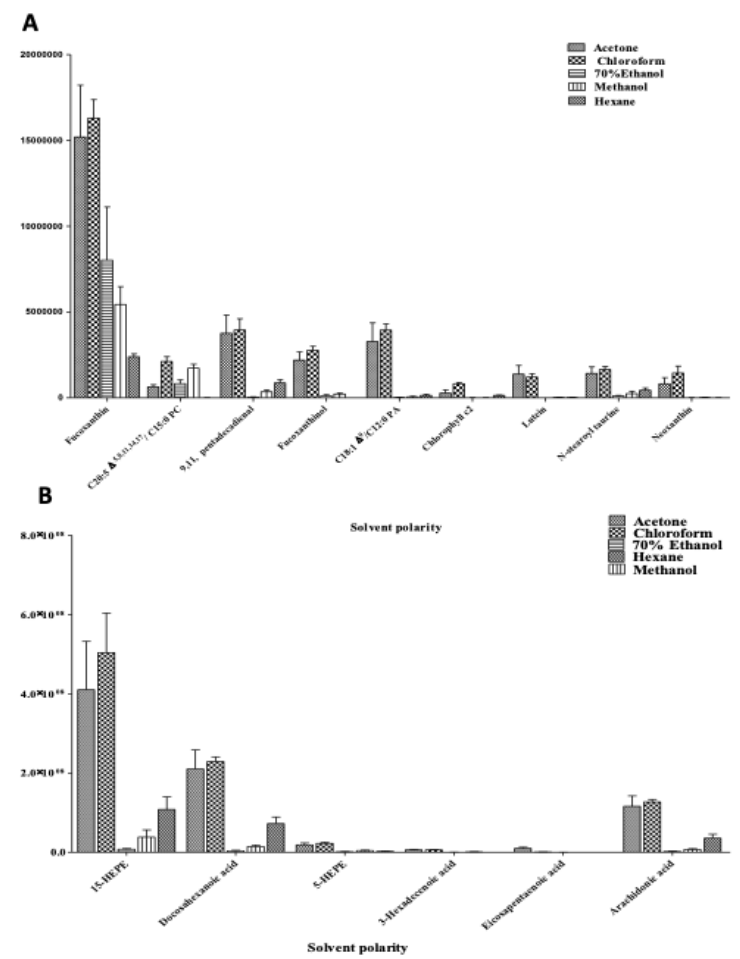

Figure 6. The Relative quantification of the identified compounds (A) Positive ionization UHPLC-MS: 6, Neoxanthin; 2, Fucoxanthinol; 11, Chlorophyll c2; 52, N-stearoyl taurine; 1, Fucoxanthin; 38, C18: $1 \Delta$ 9/C12: 0 phosphatidic acid; 51, 9,11 pentadecadienal; 3, Lutein; 36, C20: $5 \Delta 5, \Delta 8, \Delta 11, \Delta 14$, $\triangle$ 17/C15: 0 phosphatidylcholine; (B) Negative ionization UHPLC-MS: 23, Eicosapentaenoic acid; 17, 3-Hexadecenoic acid; 24, 5-HEPE; 22, Arachidonic acid; 25, 15-HEPE; 26, Docosahexaenoic acid.Data presented are based on the mean of six replicates each of the solvent systems (acetone, chloroform, hexane, methanol, $70 \%$ ethanol) \pm standard deviation (SD).

By relating the relative quantification data with PLS biplot and correlogram, fucoxanthinol, chlorophyll c2 and 3-hexadecenoic acid in chloroform and acetone extracts were located on the positive sides of PC2 in the PLS biplot with strong and significant correlations. Moreover, it is noted that the content of these metabolites was slightly higher in chloroform extract than in acetone extract. Overall, these metabolites might be the main contributors to the measured bioactivities.

\subsubsection{Validation of the Proposed Method}

Validation of the analytical method was performed to exclude interference or endogenous substance in a tested sample, ensuring the accurate identification and quantification of the targeted metabolites. In this part, ESI positive ion mode was used as the four-targeted metabolites were tentatively identified in this scan mode. Parameters such as linearity, limit of detection (LODs) and limit of quantification (LOQs) were evaluated according to FDA guideline on bioanalytical method validation [41]. 
Linearity

The linearity was measured by injecting different level of concentrations for each standard over the range $1.25-125 \mu \mathrm{g} / \mathrm{mL}$. Linearity was determined based on the least-square linear regression. In the calibration curve equations for fucoxanthin $\left(y=0.0000095 x-2.0495757 ; R^{2}=0.9967099\right)$, astaxanthin $\left(y=0.000645253 x+0.422860969 ; R^{2}=0.9998498\right)$, zeaxanthin $(y=0.0001478 x+2.9163077$; $\left.R^{2}=0.9966875\right)$, and lutein $\left(y=0.0142099 x-1.0372580 ; R^{2}=0.9990715\right)$, where $y$ represents the peak area corresponding to the concentrations of analyte, and $x$ represents the known concentration of the standard compound. Excellent linearity can be seen with determination coefficients higher than 0.98 (Table 2), using peak area as the analytical response.

Table 2. Validation parameters of the proposed method.

\begin{tabular}{cccccc}
\hline Compounds & Retention Time $\left(\mathbf{R}_{t}\right)$ & Linearity $\left(\boldsymbol{R}^{\mathbf{2}}\right)$ & Slope & LOQ $(\mathbf{m g} / \mathbf{m L})$ & LOD $(\mathbf{m g} / \mathbf{m L})$ \\
\hline Fucoxanthin & 8.15 & 0.9994 & $1.84 \times 10^{-5}$ & 0.0000162 & 0.0000049 \\
Astaxanthin & 9.51 & 0.9998 & 0.00065 & 0.0001579 & 0.0000474 \\
Zeaxanthin & 10.52 & 0.9967 & 0.00015 & 0.0000019 & 0.0000006 \\
Lutein & 10.53 & 0.9991 & 0.01421 & 0.0029388 & 0.0008816 \\
\hline
\end{tabular}

\section{LOD and LOQ}

LODs and LOQs were defined as the lowest concentration levels injected which yielded signal-to-noise $(\mathrm{S} / \mathrm{N})$ ratios of 3 and 10, respectively, at which the concentration is reliable for differentiating the signal produced by the analyte peak from the background noise. The LODs ranged from $4.68335 \times 10^{-8} \mathrm{mg} / \mathrm{mL}$ to $0.000881644 \mathrm{mg} / \mathrm{mL}$, and the LOQs ranged from $1.56112 \times 10^{-7}$ to $0.002938813 \mathrm{mg} / \mathrm{mL}$ (Table 2). These values were adequate for confirmation of the quantity of the targeted metabolites in real matrix samples.

Application of Method: Quantification of the Targeted Metabolites in Active Extracts of C. calcitrans

The optimized UHPLC-MS/MS method was then applied to chloroform and acetone extracts of the microalgal diatom C. calcitrans and the quantitative results are shown in Table 3 . The present method detected relatively high concentration values for fucoxanthin in the extract in comparison with astaxanthin, zeaxanthin and lutein. The observed results for the concentration of fucoxanthin are consistent with the results of a previous study in which the concentrations of these compounds were measured by the HPLC technique [42]. The compound present at the second highest concentration was astaxanthin, followed by lutein and zeaxanthin.

Table 3. The concentration of targeted metabolites in chloroform and acetone extracts of microalgal diatom C. calcitrans.

\begin{tabular}{ccc}
\hline Extract & Metabolites & $\begin{array}{c}\text { Concentration in Diatom in 100 mg of } \\
\text { Extracts }(\mu \mathrm{g} / \mathbf{m g})\end{array}$ \\
\hline \multirow{3}{*}{ Chloroform } & Fucoxanthin & $1.2537 \pm 0.0896$ \\
& Astaxanthin & $0.3794 \pm 0.0263$ \\
& Zeaxanthin & $0.1503 \pm 0.0001$ \\
Acetone & Lutein & $0.1513 \pm 0.0584$ \\
\hline \multirow{3}{*}{ Fucoxanthin } & $1.3031 \pm 0.0521$ \\
& Astaxanthin & $0.4346 \pm 0.0438$ \\
& Zeaxanthin & $0.1582 \pm 0.0003$ \\
& Lutein & $0.2414 \pm 0.0325$ \\
\hline
\end{tabular}




\section{Materials and Methods}

\subsection{Chemicals and Samples}

All aqueous and organic solvents used were LC/MS grade. Water, acetonitrile and methanol were obtained from Thermo Fisher Scientific (Bremen, Germany). Ammonium formate and formic acid were also supplied by Thermo Fisher Scientific (Bremen, Germany). The reference standards of carotenoids: (1) fucoxanthin, (2) astaxanthin, (3) zeaxanthin, and (4) lutein were purchased from ChromaDex, Inc. (Irvine, CA, USA). All chemicals and solvents were of analytical grade or higher purity. The microalga Chaetoceros calcitrans was supplied by Laboratory of Marine Biotechnology, Institute Biosciences, Universiti Putra Malaysia, where they obtained the algal biomass from Pantai Morib, Selangor. Stocks of the microalga were kept in $500 \mathrm{~mL}$ borosilicate glass fitted with cotton wool bungs. All stock-cultures were regularly cultivated every three to four weeks.

The microalga biomass production was accomplished in batch culture systems consisting of $5 \mathrm{~L}$ modified plastic bottle equipped with inlet and outlet tubes for aeration. The microalga was grown with aeration with mixture of air (at rate $0.2 \mathrm{~L} / \mathrm{min}$ ) and $\mathrm{CO}_{2}$ (containing 1-2\%) in presence of light (double fluorescence lamp unit, $300 \mu \mathrm{mol}$ photon $\mathrm{m}^{-2} \mathrm{~s}^{-1}, 18 \mathrm{hrs}$ of light) at room temperature $\left(25^{\circ} \mathrm{C}\right)$. During the culture for 7 days, the $\mathrm{pH}$ of the medium was maintained below 8.0 by the bubbling of air containing $\mathrm{CO}_{2}$. These are important factors for better growth condition. Besides, the microalga biomass production was cultivated in the autoclaved pure seawater with a salinity of 30 parts per thousand (ppt) on a standard $\mathrm{f} / 2$ media that comprised of: filtered natural seawater, monosodium phosphate $\left(\mathrm{NAH}_{2} \mathrm{PO}_{4} \cdot 2 \mathrm{H}_{2} \mathrm{O}\right)$, and sodium nitrate, sodium metasilicate nonahydrate $\left(\mathrm{Na}_{2} \mathrm{SiO}_{3} \cdot 9 \mathrm{H}_{2} \mathrm{O}\right)$, trace metal solution (ferric chloride hexahydrate $\left(\mathrm{FeCl}_{3} \cdot 6 \mathrm{H}_{2} \mathrm{O}\right)$, EDTA disodium dehydrate, $\left(\mathrm{Na}_{2} \mathrm{EDTA} .2 \mathrm{H}_{2} \mathrm{O}\right)$, sodium molybdate dehydrate $\left(\mathrm{Na}_{2} \mathrm{MoO}_{4} \cdot 2 \mathrm{H}_{2} \mathrm{O}\right)$, zinc sulfate heptahydrate $\left(\mathrm{ZnSO}_{4} \cdot 7 \mathrm{H}_{2} \mathrm{O}\right)$, copper(II) sulfate pentahydrate $\left(\mathrm{CuSO}_{4} \cdot 5 \mathrm{H}_{2} \mathrm{O}\right)$, cobaltous chloride hexahydrate $\left(\mathrm{CoCl}_{2} \cdot 6 \mathrm{H}_{2} \mathrm{O}\right)$, manganese(II) chloride tetrahydrate $\left(\mathrm{MnCl}_{2} \cdot 4 \mathrm{H}_{2} \mathrm{O}\right.$ ) as well as vitamin solution (distilled water, thiamine $\mathrm{HCl}$ (Vitamin B1), biotin (Vitamin B7), cyanocobalamin (Vitamin B12). Solution B (zinc chloride, cobaltous chloride, ammonium molybdate, cupric sulphate, concentrated $\mathrm{HCl}$, filtered natural; water), Solution $\mathrm{C}$ (Vitamin B1, Vitamin B12, fresh water), and Solution D (sodium metasilicate nonahydrate, fresh water) for the growth of microalga. The whole growth medium was adjusted to $\mathrm{pH} 8$.

After the cultures were allowed to grow till 5-8 days (end of exponential phase/start of the stationary phase) and considered achieved highest densities ( $\left.0.5 \mathrm{DW}\left(\mathrm{g} \mathrm{per} \mathrm{L}^{-1}\right)\right)$, this alga biomass was harvested by centrifugation using high-speed Sorvall Evolution RC centrifuge (Thermo Electron Corporation, NC, USA) at speed $12,000 \mathrm{rpm}$ at $4{ }^{\circ} \mathrm{C}$, for $5 \mathrm{~min}$, necessary for sedimentation. After centrifugation, pellets were washed by resuspension in distilled water and repeated the centrifugation to free of from remaining salts. Then, the harvested microalga was freeze-dried by using ScanVac CoolSafe Freeze DryerTM (Labogene, Lynge, Denmark) kept at $-80^{\circ} \mathrm{C}$. The extract was kept in dim light at $-20^{\circ} \mathrm{C}$ until use. The grounded microalga powder was then subjected to five different solvent extractions including $100 \%$ chloroform, 100\% acetone, $100 \%$ methanol, $70 \%$ ethanol, and $100 \%$ hexane and ultrasound assisted extraction was applied. In each sample, the microalga sample was kept constant, i.e., $100 \mathrm{mg}$ of microalga sample in $50 \mathrm{~mL}$ of solvent. Sonication was carried out of $30 \mathrm{~min}$ using an ultrasonic water bath (SK8210HP, Shanghai KUDOS Ultrasonic Instrument Co. Ltd., China) at room temperature. The extraction procedure was repeated three times for each sample. Crude extracts were then filtered, vacuum-evaporated, freeze-dried, and kept in a chiller $\left(-20{ }^{\circ} \mathrm{C}\right)$ until further analysis.

\subsection{In Vitro Preliminary Assays}

\subsubsection{2,2-Diphenyl-1-picrylhydrazyl (DPPH) Radical Scavenging Assay}

The antioxidant potential of microalga diatom C. calcitrans was determined based on the DPPH free radical scavenging assay according to the method reported in our previous study [3]. Each sample 
was prepared in dimethyl sulfoxide (DMSO) at a stock concentration of $1000 \mathrm{ppm}$. Quercetin was used as standard. The results were expressed as a percentage of DPPH inhibition.

\subsubsection{Nitric Oxide (NO) Inhibitory Assay}

The nitric oxide inhibitory by C. calcitrans extracts was determined using the Griess assay as described in detail in our previous study [3]. The RAW 264.7 cell lines were incubated at $37^{\circ} \mathrm{C}$ in Dulbecco's Modified Eagle's medium (DMEM) media supplemented with $10 \%$ (v/v) inactivated fetal bovine serum and $100 \mathrm{U} / \mathrm{mL}$ penicillin/streptomycin under a water-saturated atmosphere of $95 \%$ air and $5 \% \mathrm{CO}_{2}$. The cells were seeded in 96-well culture plates $\left(5 \times 10^{4}\right.$ cells/well $)$ and allowed to adhere for $17 \mathrm{~h}$ at $37^{\circ} \mathrm{C}$. The cells were incubated with $10 \mu \mathrm{g} / \mathrm{mL}$ of LPS and 200 units/mL of recombinant murine IFN- $\gamma$ in the absence or presence of the test compounds. Cucurmin was used as a positive control. To quantify the NO synthesis, the nitrite concentration was measured by the Griess reaction using the supernatant of the RAW 264.7 cell. The remaining cells in the incubated wells were measured for cell viability using 3-(4,5-dimethylthiazol-2-yl)-2,5diphenyltetrazolium bromide (MTT) reagent.

\subsection{Targeted Metabolite Profiling Using UHPLC-ESI-Orbitrap MS}

\subsubsection{Sample Preparation of UHPLC-ESI-Orbitrap MS Approach}

The sample extracts were dissolved in LCMS grade methanol respectively, at concentrations $2 \mathrm{mg}$ in $1 \mathrm{~mL}$. Then, the dissolved extract was vortexed for 3-4 min and sonicated for $5 \mathrm{~min}$. All the dissolved microalga extracts were filtered through a $0.22 \mu \mathrm{m}$ Nylon membrane filter (Millipore, Billerica, MA, USA) before UHPLC-MS analysis.

\subsubsection{UHPLC-ESI-Orbitrap MS Analysis}

Chromatographic separation was performed on ultra-high performance liquid chromatography (UHPLC) system consisted of an Ultimate 3000 LC system (Thermo Scientific ${ }^{\mathrm{TM}}$ Dionex $^{\mathrm{TM}}$, Sunnyvale, CA, USA), to a surveyor UHPLC binary pump, a photodiode array detector (PDA) detector, scanning from 200 to $600 \mathrm{~nm}$ and auto-sampler (Exactive ${ }^{\mathrm{TM}}$, Thermo Fisher Scientific, Bremen, and Germany). High-resolution MS analysis was carried out using Thermo Fisher Scientific ${ }^{\mathrm{TM}} \mathrm{Q}$ Exactive ${ }^{\mathrm{TM}}$ Focus Quadrupole-Orbitrap mass spectrometer (Thermo Fisher Scientific, San Jose, CA, USA) operated at 70,000 resolutions (FWHM), which was equipped with a heated electrospray ionisation (HESI II) source. The UHPLC-ESI-Orbitrap MS system was controlled by Exactive Tune 1.1 and Xcalibur 2.0 software (Thermo Fisher Scientific, San José, CA, USA).

This following procedure was performed in accordance with the procedure described by $\mathrm{Fu}$, et al. [43] and Bijttebier, et al. [18], with modifications. An analytical column used were ACQUITY UPLC HSS T3 $1.8 \mu \mathrm{m}(2.1 \times 150 \mathrm{~mm})$ (Waters, Manchester, UK). The flow rate was $0.25 \mathrm{~mL} / \mathrm{min}$ and the column temperature were maintained at $30^{\circ} \mathrm{C}$. The mobile phase consisted of eluent $\mathrm{A}$, a mixture acetonitrile $(\mathrm{ACN}) /$ methanol $(\mathrm{MEOH}) / 2$-propanol (70:20:10, v/v/v) containing $10 \mathrm{mM}$ ammonium formate with $1 \%$ formic acid, and eluent $\mathrm{B}, 10 \mathrm{mM}$ ammonium formate with $1 \%$ formic acid in water. The following gradient was used: $0 \mathrm{~min}, 70 \% \mathrm{~A} ; 1.17 \mathrm{~min}, 70 \% \mathrm{~A} ; 7 \mathrm{~min}, 90 \% \mathrm{~A} ; 9.73 \mathrm{~min}, 100 \% \mathrm{~A}$; $30 \mathrm{~min}, 100 \% \mathrm{~A}, 31 \mathrm{~min}, 70 \% \mathrm{~A} ; 35 \mathrm{~min} ; 70 \% \mathrm{~A}$ until the end of the run at $30 \mathrm{~min}[44,45]$. The sample injection volume was set at $2 \mu \mathrm{L}$. All the tentatively identified analytes eluting over 0-30 min while the last 5 min were used for column cleaning and re-equilibration.

The ESI source was operated in the positive full scan mode and the parameters were as follows: sheath gas flow rate of 50 arbitary (arb) unit, auxillary gas flow rate of 10 arbs, electrospray voltage of $4.0 \mathrm{kV}$, capillary temperature of $350{ }^{\circ} \mathrm{C}$, heater temperature of $300{ }^{\circ} \mathrm{C}$, S-lens RF level of 55 , the collision energy of $10 \%$. Mass spectrometric analysis subsequently was performed for data-dependent acquisition (DDA) with priority to mass-to-charge ratios $(\mathrm{m} / \mathrm{z}$ ) of parent compounds and their expected metabolites (separate inclusion lists for fucoxanthin, astaxanthin, lutein, and zeaxanthin). Discovery mode was chosen to ensure the recording of $\mathrm{MS}^{2}$ spectra of precursor ions not in the inclusion list. The settings 
for full-scan data acquisition were as follows: polarity, positive; resolution, 70,000; scan range, $\mathrm{m} / \mathrm{z}$ 100-1500; automatic gain control (AGC) target, 1e6; auto maximum injection time (IT); microscans, 1; spectrum data type, profile. The settings for the DDA mode were as follows: dd-MS ${ }^{2}$, discovery; resolution, 17,500; isolation window, $3.0 \mathrm{~m} / \mathrm{z}$; AGC target, 5e4; maximum injection time, $250 \mathrm{~ms}$; high-collision dissociation cell with stepped normalized collision energy, 10; loop count, 1; minimum AGC target, 8e3 (corresponds to auto signal intensity threshold); exclude isotopes, on; and spectrum data type, profile. Mass calibration was conducted prior to analysis according to the manufacturer's recommendations using external mass calibration. The same experiment was also performed in the negative ion mode. Data were acquired and analyzed using Xcalibur 2.0.7 software (Thermo Fisher Scientific). The option of "all ion fragmentation" using the high-energy collision dissociation (HCD) cell was applied to investigate the confirmation potential of generated fragments and was turned on during the actual analysis [46].

Metabolites were tentatively identified based on retention time, UV-vis spectral characteristic features and with the exact mass measurement. The identification of metabolites was further confirmed by comparing the retention time and MS/MS spectra with commercially available standards or matching accurate mass and fragment information with Metabolomics workbench (http://www. metabolomicsworkbench.org/), MetFrag (https://msbi.ipb-halle.de/MetFrag/), METLIN (http://metlin. scripps.edu), GNPS (https://gnps.ucsd.edu/), ReSpect (http://spectra.psc.riken.jp/) and HMDB (http: $/ /$ www.hmdb.ca/) databases. The exact $m / z$ and retention time of each metabolite were used for targeted metabolomic analyses using the single ion monitoring (SIM) by setting for a narrower mass range as provided in Xcalibur software package. Furthermore, the identification of the metabolites was further supported by the mass error calculations (reported as ppm) whereby the lowest values suggested higher probability for an accurate metabolite identification and vice-versa. Quality control (QC) were performed once every ten of LCMS runs to monitor variation, quality of the MS data being generated and reproducibility of the analytical instrument. This method is extremely worthwhile as QC was used to check for intensity of peak signals and drift of the retention time.

\subsubsection{UHPLC-ESI-Orbitrap MS Data Preprocessing}

The raw data were first transformed into centroid mode data of mzXML format using MSConvert tool from Proteowizard program (http://proteowizard.sourceforge.net/). Then data pretreatment which include non-linear retention time correction, peak filtration, calibration, extraction, peak picking and matching was performed by using open source XCMS online software (https://xcmsonline. scripps.edu/). Data were processed by using the following parameters as recommended for UHPLC (Q-Exactive) $[47,48]$.

The obtained peak lists of the datasets were normalized to the total integrated area per sample in Microsoft Excel. The region from retention time 0 to $0.98 \mathrm{~min}$ was excluded from the data results because not significant for further metabolome analyses. Data result sets containing all the $\mathrm{m} / \mathrm{z}$ value of UHPLC-ESI-Orbitrap MS datasets, retention time and ion peak area of each sample, which corresponds to the intensity of certain metabolite, were exported to the multivariate statistical software SIMCA (version 14.0, Umetrics, Umea, Sweden) for the subsequent unsupervised and supervised analysis, including partial component analysis (PCA) and partial least square analysis (PLS).

\subsection{Targeted Metabolites Quantification Using UHPLC-ESI-MS/MS Orbitrap}

\subsubsection{Relative Quantification of the Identified Metabolites Using UHPLC-ESI-MS/MS Orbitrap} Approach

Relative quantification of the identified metabolites was measured using their representative mean peak area of the MS signals, after preprocessing method. The chromatographic peaks in MS data with distinct $\mathrm{m} / \mathrm{z}$ values, but at similar retention times was assigned to define each metabolite of interest. The changes in metabolite levels of different solvent extractions were quantitatively evaluated 
and displayed in bar chart using SPSS 16.0 software (IBM, Chicago, IL, USA) and GraphPad Prism Version 5.01 (GraphPad Prism Software Inc., San Diego, CA, USA). Tukey's significant difference multiple-comparison test was performed to evaluate the significant differences between the extracts.

\subsubsection{Targeted Metabolites Quantification Using UHPLC-ESI-MS/MS Orbitrap Analysis}

A total of four standards including fucoxanthin, astaxanthin, zeaxanthin and lutein were used. Each standard with its precursor and fragment ions predefined by running full scan mass acquisition in positive ion mode from $\mathrm{m} / \mathrm{z} 100$ to 1500 . These data were used to search the appropriate retention time windows (RTWs) for confirming the presence and the mass spectral identity of the targeted carotenoids in the extract. The setting for ESI interface parameters were similar as performed in Section 2.3.2. The injection volume for each standard was set to $2 \mu \mathrm{L}$ and they were prepared at 5-10 serial dilutions in a screw-capped amber glass vials to plot the calibration curve (ranging from $1.25-125 \mu \mathrm{g} / \mathrm{mL}$ ). For calculating the concentration of each targeted carotenoid compound in real samples (microalga extracts), the area under the peak was used and expressed as micrograms per milligram of microalga extract.

\subsection{Statistical Analysis}

Results are presented as the mean of six replicates \pm SD. Statistical significance between groups was determined by one-way ANOVA. The significant level was established at $p$-value set at $<0.05$.

\section{Conclusions}

Metabolomics approach using high resolution UHPLC-ESI-Orbitrap MS has proven to be an effective tool in evaluating variation among different microalga extracts. A total of 54 metabolites were unambiguously or tentatively identified. The UHPLC-ESI-Orbitrap MS allowed the additional information for the structural characterization of targeted metabolites. However, a comparison of the data with the available databases remains insufficient for identification due to almost identical positional isomers. The only confident way for complex structural analysis for identification metabolites and proposed structures are by using methods such as NMR spectroscopy, methyl esterification (FAME) and GCMS analysis. The present study proposes that extracts prepared from chloroform extract followed by acetone extract had stronger DPPH free radical scavenging capacities and inhibition effect of NO production than extracts prepared from the other solvents. Chemometric analysis and quantification by UHPLC-ESI-MS/MS approaches suggest that fucoxanthinol, chlorophyll c2, and 3-hexadecenoic acid in chloroform and acetone extracts were the main contributors to the antioxidant and anti-inflammatory properties of microalga. Although the targeted metabolites included fucoxanthin, lutein, zeaxanthin and astaxanthin were not the main bioactivity contributors, their synergistic effect towards the bioactivity should not be disregarded. This study facilitates the quality control and pharmaceutical authentication of $C$. calcitrans for safe and efficacious use in the food supplement industry and in producing feed for animals in marine aquaculture food products, and therapeutic functions. It could also provide a basis for further in vivo studies of $C$. calcitrans.

Supplementary Materials: The following are available online at http://www.mdpi.com/1660-3397/18/8/403/s1, Figure S1-S4: UHPLC-ESI-Orbitrap MS base peak chromatogram of the acetone, $70 \%$ ethanol, methanol and hexane extracts. Figure S5: The validation PLS models using permutation test for positive ionization (A: NO, B: $\mathrm{DPPH}$ ) and negative ionisation (C: NO, D: DPPH) UHPLC-MS based metabolite profiling data of C. calcitrans whereas Figure S6: The PLS derived relationship between observed vs. predicted for positive ionization (A: NO, B: DPPH) and negative ionization (C: NO, D: DPPH) UHPLC-MS based metabolite profiling data of C. calcitrans. Table S1: Relative quantification of compounds in the extracts of Chaetoceros calcitrans.

Author Contributions: F.A. and A.A. conceived and designed the experiments; N.N. and A.A. conducted the microalgae cultivation; A.A. performed the experiments; A.A., R.R. and M.M. analyzed the data; K.S. and I.S.I. provided reagents/materials/analysis tools; A.A., F.A. and M.M. wrote, edited and revised the paper. All authors have read and agreed to the published version of the manuscript. 
Funding: This research was funded by the Japan Science and Technology Agency (JST)/Japan International Cooperation Agency (JICA), Science and Technology Research Partnership for Sustainable Development (SATREPS) through the project for Continuous Operation System for Microalgae Production Optimized for Sustainable Tropical Aquaculture (COSMOS), and the SATREPS-COSMOS Matching Fund from the Ministry of Higher Education Malaysia (MOHE) (JICA-JST-COSMOS PROJECT 2016-2020; No: 6300856).

Acknowledgments: The first author also would like to gratefully acknowledge Graduate Research Fellowship (GRF) from Universiti Putra Malaysia. The authors thank Muhammad Safwan Bustamam for helping to cultivate the microalgae.

Conflicts of Interest: The authors declare no conflict of interest.

\section{References}

1. Méndez-Martínez, Y.; García-Guerrero, M.U.; Lora-Vilchis, M.C.; Martínez-Córdova, L.R.; Arcos-Ortega, F.G.; Alpuche, J.J.; Cortés-Jacinto, E. Nutritional effect of Artemia nauplii enriched with Tetraselmis suecica and Chaetoceros calcitrans microalgae on growth and survival on the river prawn Macrobrachium americanum larvae. Aquacult. Int. 2018, 26, 1001-1015. [CrossRef]

2. Zanella, L.; Pertile, P.; Massironi, M.; Caviola, E. Extracts of Microalgae and Their Application. U.S. Patent 9,974,819, 22 May 2018.

3. Azizan, A.; Bustamam, M.S.A.; Maulidiani, M.; Shaari, K.; Ismail, I.S.; Nagao, N.; Abas, F. Metabolite profiling of the microalgal diatom Chaetoceros calcitrans and correlation with antioxidant and nitric oxide inhibitory activities via ${ }^{1} \mathrm{H}$ NMR-based metabolomics. Mar. Drugs 2018, 16, 154. [CrossRef]

4. Dang, T.T.; Bowyer, M.C.; Van Altena, I.A.; Scarlett, C.J. Comparison of chemical profile and antioxidant properties of the brown algae. Int. J. Food Sci. Technol. 2018, 53, 174-181. [CrossRef]

5. Yamano, N.; Mizoguchi, T.; Fujii, R. The pH-dependent photophysical properties of chlorophyll-c bound to the light-harvesting complex from a diatom, Chaetoceros calcitrans. J. Photochem. Photobiol. A Chem. 2018, 358, 379-385. [CrossRef]

6. Juin, C.; Bonnet, A.; Nicolau, E.; Bérard, J.B.; Devillers, R.; Thiéry, V.; Cadoret, J.-P.; Picot, L. UPLC-MSE profiling of phytoplankton metabolites: Application to the identification of pigments and structural analysis of metabolites in Porphyridium purpureum. Mar. Drugs 2015, 13, 2541-2558. [CrossRef]

7. Hano, T.; Tomaru, Y. Metabolomics-based approach to explore growth phase-dependent markers in cultured diatom Chaetoceros tenuissimus. J. Chrom. B 2019, 1128, 121779. [CrossRef]

8. Kustka, A.B.; Allen, A.E.; Morel, F.M. Sequence analysis and transcriptional regulation of iron acquisition genes in two marine diatoms ${ }^{1}$. J. Phycol. 2007, 43, 715-729. [CrossRef]

9. Allen, A.E.; LaRoche, J.; Maheswari, U.; Lommer, M.; Schauer, N.; Lopez, P.J.; Finazzi, G.; Fernie, A.R.; Bowler, C. Whole-cell response of the pennate diatom Phaeodactylum tricornutum to iron starvation. Proc. Natl. Acad. Sci. USA 2008, 105, 10438-10443. [CrossRef]

10. Zeng, M.; Hao, W.; Zou, Y.; Shi, M.; Jiang, Y.; Xiao, P.; Lei, A.; Hu, Z.; Zhang, W.; Zhao, L.; et al. Fatty acid and metabolomic profiling approaches differentiate heterotrophic and mixotrophic culture conditions in a microalgal food supplement 'Euglena'. BMC Biotechnol. 2016, 16, 49. [CrossRef]

11. Bianco, G.; Agerbirk, N.; Losito, I.; Cataldi, T.R. Acylated glucosinolates with diverse acyl groups investigated by high resolution mass spectrometry and infrared multiphoton dissociation. Phytochemistry 2014, 100, 92-102. [CrossRef]

12. Cataldi, T.R.; Bianco, G.; Abate, S.; Losito, I. Identification of unsaturated N-acylhomoserine lactones in bacterial isolates of Rhodobacter sphaeroides by liquid chromatography coupled to electrospray ionization-hybrid linear ion trap-Fourier transform ion cyclotron resonance mass spectrometry. Rapid Commun. Mass Spectrom. 2011, 25, 1817-1826. [CrossRef]

13. Porzel, A.; Farag, M.A.; Mülbradt, J.; Wessjohann, L.A. Metabolite profiling and fingerprinting of Hypericum species: A comparison of MS and NMR metabolomics. Metabolomics 2014, 10, 574-588. [CrossRef]

14. Abdul-Hamid, N.A.; Abas, F.; Ismail, I.S.; Tham, C.L.; Maulidiani, M.; Mediani, A.; Swarup, S.; Umashankar, S.; Zolkeflee, N.K.Z. Metabolites and biological activities of Phoenix dactylifera L. pulp and seeds: A comparative MS and NMR based metabolomics approach. Phytochem. Lett. 2019, 31, 20-32. [CrossRef]

15. Bird, S.S.; Marur, V.R.; Sniatynski, M.J.; Greenberg, H.K.; Kristal, B.S. Lipidomics profiling by high-resolution LC-MS and high-energy collisional dissociation fragmentation: Focus on characterization of mitochondrial cardiolipins and monolysocardiolipins. Anal. Chem. 2010, 83, 940-949. [CrossRef] 
16. Fu, W.; Magnúsdóttir, M.; Brynjólfson, S.; Palsson, B.Ø.; Paglia, G. UPLC-UV-MS E analysis for quantification and identification of major carotenoid and chlorophyll species in algae. Anal. Bioanal. Chem. 2012, 404, 3145-3154. [CrossRef] [PubMed]

17. Airs, R.L.; Llewellyn, C.A. Improved detection and characterisation of fucoxanthin-type carotenoids: Novel pigments in Emiliiana Huxleyi (prymnesiophyceae). J. Phycol. 2006, 42, 391-399. [CrossRef]

18. Bijttebier, S.K.; D’Hondt, E.; Hermans, N.; Apers, S.; Voorspoels, S. Unravelling ionization and fragmentation pathways of carotenoids using orbitrap technology: A first step towards identification of unknowns. J. Mass Spectrom. 2013, 48, 740-754. [CrossRef]

19. Van Breemen, R.B.; Dong, L.; Pajkovic, N.D. Atmospheric pressure chemical ionization tandem mass spectrometry of carotenoids. Int. J. Mass Spectrom. 2012, 312, 163-172. [CrossRef]

20. Chen, K.; Ríos, J.J.; Pérez-Gálvez, A.; Roca, M. Comprehensive chlorophyll composition in the main edible seaweeds. Food Chem. 2017, 228, 625-633. [CrossRef] [PubMed]

21. Kerwin, J.L.; Wiens, A.M.; Ericsson, L.H. Identification of fatty acids by electrospray mass spectrometry and tandem mass spectrometry. J. Mass Spectrom. 1996, 31, 184-192. [CrossRef]

22. Mansour, M.P.; Frampton, D.M.; Nichols, P.D.; Volkman, J.K.; Blackburn, S.I. Lipid and fatty acid yield of nine stationary-phase microalgae: Applications and unusual C24-C28 polyunsaturated fatty acids. J. Appl. Phycol. 2005, 17, 287-300. [CrossRef]

23. Lang, I.; Hodac, L.; Friedl, T.; Feussner, I. Fatty acid profiles and their distribution patterns in microalgae: A comprehensive analysis of more than 2000 strains from the SAG culture collection. BMC Plant Biol. 2011, 11, 124-140. [CrossRef]

24. Rettner, J.; Markus, W.; Meyer, N.; Werz, O.; Georg, P. Survey of the C20 and C22 Oxylipin Family in Marine Diatoms. Tetrahedron Lett. 2018, 59, 828-831. [CrossRef]

25. Liu, B.; Vieler, A.; Li, C.; Jones, A.D.; Benning, C. Triacylglycerol profiling of microalgae Chlamydomonas reinhardtii and Nannochloropsis oceanica. Bioresour. Technol. 2013, 146, 310-316. [CrossRef]

26. Hsu, F.F.; Turk, J. Characterization of phosphatidylinositol, phosphatidylinositol-4-phosphate, and phosphatidylinositol-4, 5-bisphosphate by electrospray ionization tandem mass spectrometry: A mechanistic study. J. Am. Soc. Mass Spectrom. 2000, 11, 986-999. [CrossRef]

27. Murphy, R.C.; Axelsen, P.H. Mass spectrometric analysis of long-chain lipids. Mass Spectrom. Rev. 2011, 30, 579-599. [CrossRef]

28. Danielewicz, M.A.; Anderson, L.A.; Franz, A.K. Triacylglycerol profiling of marine microalgae by mass spectrometry. J. Lipid Res. 2011, 52, 2101-2108. [CrossRef]

29. Yao, L.; Gerde, J.A.; Lee, S.L.; Wang, T.; Harrata, K.A. Microalgae lipid characterization. J. Agric. Food Chem. 2015, 63, 1773-1787. [CrossRef]

30. Kumari, P.; Kumar, M.; Reddy, C.R.K.; Jha, B. Algal lipids, fatty acids and sterols. In Functional Ingredients from Algae for Foods and Nutraceuticals; Dominguez, H., Ed.; Woodhead Publishing Limited: Cambridge, UK, 2013; pp. 87-134.

31. Da Costa, E.; Silva, J.; Mendonça, S.H.; Abreu, M.H.; Domingues, M.R. Lipidomic approaches towards deciphering glycolipids from microalgae as a reservoir of bioactive lipids. Mar. Drugs 2016, 14, 101. [CrossRef]

32. Lu, S.; Wang, J.; Ma, Q.; Yang, J.; Li, X.; Yuan, Y.J. Phospholipid metabolism in an industry microalga Chlorella sorokiniana: The impact of inoculum sizes. PLoS ONE 2013, 8, e70827. [CrossRef]

33. Brembu, T.; Mühlroth, A.; Alipanah, L.; Bones, A.M. The effects of phosphorus limitation on carbon metabolism in diatoms. Philos. Trans. R. Soc. B 2017, 372, 20160406. [CrossRef] [PubMed]

34. Barofsky, A.; Pohnert, G. Biosynthesis of polyunsaturated short chain aldehydes in the diatom Thalassiosira rotula. Org. Lett. 2007, 9, 1017-1020. [CrossRef] [PubMed]

35. Liang, M.H.; Zhu, J.; Jiang, J.G. Carotenoids biosynthesis and cleavage related genes from bacteria to plants. Crit. Rev. Food Sci. Nutr. 2018, 58, 2314-2333. [CrossRef]

36. Alonso, D.L.; Belarbi, E.H.; Rodríguez-Ruiz, J.; Segura, C.I.; Giménez, A. Acyl lipids of three microalgae. Photochemistry 1998, 47, 1473-1481. [CrossRef]

37. Kaiser, B.K.; Carleton, M.; Hickman, J.W.; Miller, C.; Lawson, D.; Budde, M.; Cross, F. Fatty aldehydes in cyanobacteria are a metabolically flexible precursor for a diversity of biofuel products. PLoS ONE 2013, 8, e58307. [CrossRef] 
38. Sachindra, N.M.; Sato, E.; Maeda, H.; Hosokawa, M.; Niwano, Y.; Kohno, M.; Miyashita, K. Radical scavenging and singlet oxygen quenching activity of marine carotenoid fucoxanthin and its metabolites. J. Agric. Food Chem. 2007, 55, 8516-8522. [CrossRef]

39. Plaza, M.; Santoyo, S.; Jaime, L.; Reina, G.G.B.; Herrero, M.; Señoráns, F.J.; Ibáñez, E. Screening for bioactive compounds from algae. J. Pharm. Biomed. Anal. 2010, 51, 450-455. [CrossRef]

40. Foo, S.C.; Yusoff, F.M.; Ismail, M.; Basri, M.; Chan, K.W.; Khong, N.M.; Yau, S.K. Production of fucoxanthin-rich fraction (FxRF) from a diatom, Chaetoceros calcitrans (Paulsen) Takano 1968. Algal Res. 2015, 12, $26-32$. [CrossRef]

41. Food and Drug Administration. Guidance for Industry: Bioanalytical Method Validation; US Department of Health and Human Services, FDA, Center for Drug Evaluation and Research: Rockville, MD, USA, 2001.

42. Foo, S.C.; Yusoff, F.M.; Ismail, M.; Basri, M.; Khong, N.M.H.; Chan, K.W.; Yau, S.K. Efficient solvent extraction of antioxidant-rich extract from a tropical diatom, Chaetoceros calcitrans (Paulsen) Takano 1968. Asian Pac. J. Trop. Biomed. 2015, 5, 834-840. [CrossRef]

43. Fu, W.; Guðmundsson, Ó.; Paglia, G.; Herjólfsson, G.; Andrésson, Ó.S.; Palsson, B.Ø.; Brynjólfsson, S. Enhancement of carotenoid biosynthesis in the green microalga Dunaliella salina with light-emitting diodes and adaptive laboratory evolution. Appl. Microbiol. Biotechnol. 2013, 97, 2395-2403. [CrossRef]

44. Rivera, S.M.; Canela-Garayoa, R. Analytical tools for the analysis of carotenoids in diverse materials. J. Chromatogr. A 2012, 1224, 1-10. [CrossRef] [PubMed]

45. Rivera, S.M.; Christou, P.; Canela-Garayoa, R. Identification of carotenoids using mass spectrometry. Mass Spectrom. Rev. 2014, 33, 353-372. [CrossRef]

46. Jora, M.; Burns, A.P.; Ross, R.L.; Lobue, P.A.; Zhao, R.; Palumbo, C.M.; Jora, M.; Burns, A.P.; Ross, R.L.; Lobue, P.A.; et al. Differentiating positional isomers of nucleoside modifications by higher-energy collisional dissociation mass spectrometry (HCD MS). J. Am. Soc. Mass Spectrom. 2018, 29, 1745-1756. [CrossRef]

47. Wei, X.; Shi, X.; Kim, S.; Zhang, L.; Patrick, J.S.; Binkley, J.; Zhang, X. Data preprocessing method for liquid chromatography-mass spectrometry-based metabolomics. Anal. Chem. 2012, 84, 7963-7971. [CrossRef]

48. Glauser, G.; Veyrat, N.; Rochat, B.; Wolfender, J.L.; Turlings, T.C. Ultra-high pressure liquid chromatography-mass spectrometry for plant metabolomics: A systematic comparison of high-resolution quadrupole-time-of-flight and single stage Orbitrap mass spectrometers. J. Chromatogr. A 2013, 1292, 151-159. [CrossRef]

(C) 2020 by the authors. Licensee MDPI, Basel, Switzerland. This article is an open access article distributed under the terms and conditions of the Creative Commons Attribution (CC BY) license (http://creativecommons.org/licenses/by/4.0/). 